\title{
Experimental flow boiling heat transfer in a small polyimide channel
}

\author{
Manuel Gómez Marzoa ${ }^{1,2,3, a}$, Gherhardt Ribatski ${ }^{3, b}$, John Richard Thome ${ }^{1, c}$ \\ ${ }^{1}$ Laboratoire de Transfert de Chaleur et Masse (LTCM), École Polytechnique Fédérale \\ de Lausanne (EPFL). EPFL-STI-IGM-LTCM, Station 9, 1015 Lausanne, Switzerland \\ ${ }^{2}$ European Centre for Nuclear Research (CERN), Geneva, CH-1211 \\ ${ }^{3}$ Heat Transfer Research Group, Escola de Engenharia de São Carlos, University of São \\ Paulo. Av. Trabalhador São Carlense, 400, Parque Arnold Schmidt, São Carlos, São \\ Paulo. Mechanical Engineering Department. 13566-590. Tel.: +55 (16) 3373-9415 \\ manuel.gomezmarzoa@epfl.ch ${ }^{\mathrm{a}}$, ribatski@sc.usp.br ${ }^{\mathrm{b}}$, john.thome@epfl.ch ${ }^{\mathrm{c}}$
}

\begin{abstract}
New experimental flow boiling heat transfer results averaged along a very low thermal conductivity polyimide channel are presented. The experimental setup consists of a horizontal, $300 \mathrm{~mm}$-long, $2.689 \mathrm{~mm}$ inner diameter polyimide tube, heated by a counter-current, external water flow. R245fa is the working fluid, at mass fluxes ranging from 100 to $500 \mathrm{~kg} \mathrm{~m}^{-2} \mathrm{~s}^{-1}$, heat fluxes from 15 to $55 \mathrm{~kW} \mathrm{~m}$, and three saturation temperatures: 35,41 and $47^{\circ} \mathrm{C}$. Heat transfer coefficient results are presented averaged over the whole polyimide channel for mean vapor qualities ranging from 0.05 to 0.8 . High-speed flow visualization was possible downstream of the polyimide tube. Parametric analysis of the results revealed a strong dependence of the heat transfer coefficients on mass flux and vapor quality, and mild influence of the heat flux and the saturation temperature. The experimental database is compared with results obtained for metallic tubes of comparable size in similar experimental facilities. Last, experimental results are contrasted with several heat transfer methods, of which a convective model for annular flow well predicts the heat transfer coefficient values and convective boiling trends.
\end{abstract}

Keywords: Heat transfer coefficient; two-phase flow; convective flow boiling; minichannel; polyimide; smooth tube. 


\section{Nomenclature}

$A_{i} \quad$ cross sectional area $\quad\left[\mathrm{m}^{-2}\right]$

Co Confinement number

$c_{p} \quad$ specific heat at a constant pressure $\quad\left[\mathrm{J} \mathrm{kg}^{-1} \mathrm{~K}^{-1}\right]$

D diameter [m]

$G \quad$ mass flux $\quad\left[\mathrm{kg} \mathrm{m}^{-2} \mathrm{~s}^{-1}\right]$

$h \quad$ heat transfer coefficient $\quad\left[\mathrm{W} \mathrm{m}^{-2} \mathrm{~K}^{-1}\right]$

$k \quad$ thermal conductivity $\quad\left[\mathrm{W} \mathrm{m}^{-1} \mathrm{~K}^{-1}\right]$

$L \quad$ polyimide channel heated length $\quad[\mathrm{m}]$

$\dot{m} \quad$ mass flow rate $\quad\left[\mathrm{kg} \mathrm{s}^{-1}\right]$

$M A E$ mean absolute error $\quad[\%]$

$M R E$ mean relative error $\quad[\%]$

$p \quad$ pressure $\quad[\mathrm{kPa}]$

$q$ heat flux $\quad\left[\mathrm{kW} \mathrm{m}^{-2}\right]$

$\dot{Q}$ heat load $\quad$ [W]

$R \quad$ thermal resistance $\quad\left[\mathrm{K} \mathrm{W}^{-1}\right]$

Re Reynolds number $\quad[-]$

$S C$ subcooling $\quad[\mathrm{K}]$

$\begin{array}{lll}T & \text { temperature } & {\left[{ }^{\circ} \mathrm{C}\right]}\end{array}$

$v \quad$ specific volume $\quad\left[\mathrm{m}^{3} \mathrm{~kg}^{-1}\right]$

$x \quad$ vapor quality

$\Delta p \quad$ pressure difference $\quad[\mathrm{kPa}]$

$\Delta T \quad$ temperature difference $\quad[\mathrm{K}]$

$\varepsilon \quad$ void fraction $\quad[-]$

$\lambda_{n \%} \quad$ fraction of data predicted within a $\pm \mathrm{n} \%$ error range [\%]

$\mu \quad$ dynamic viscosity $\quad[\mathrm{Pa} \mathrm{s}]$

$\rho$ density $\quad\left[\mathrm{kg} \mathrm{m}^{-3}\right]$

\section{Subscripts}

ann annulus 


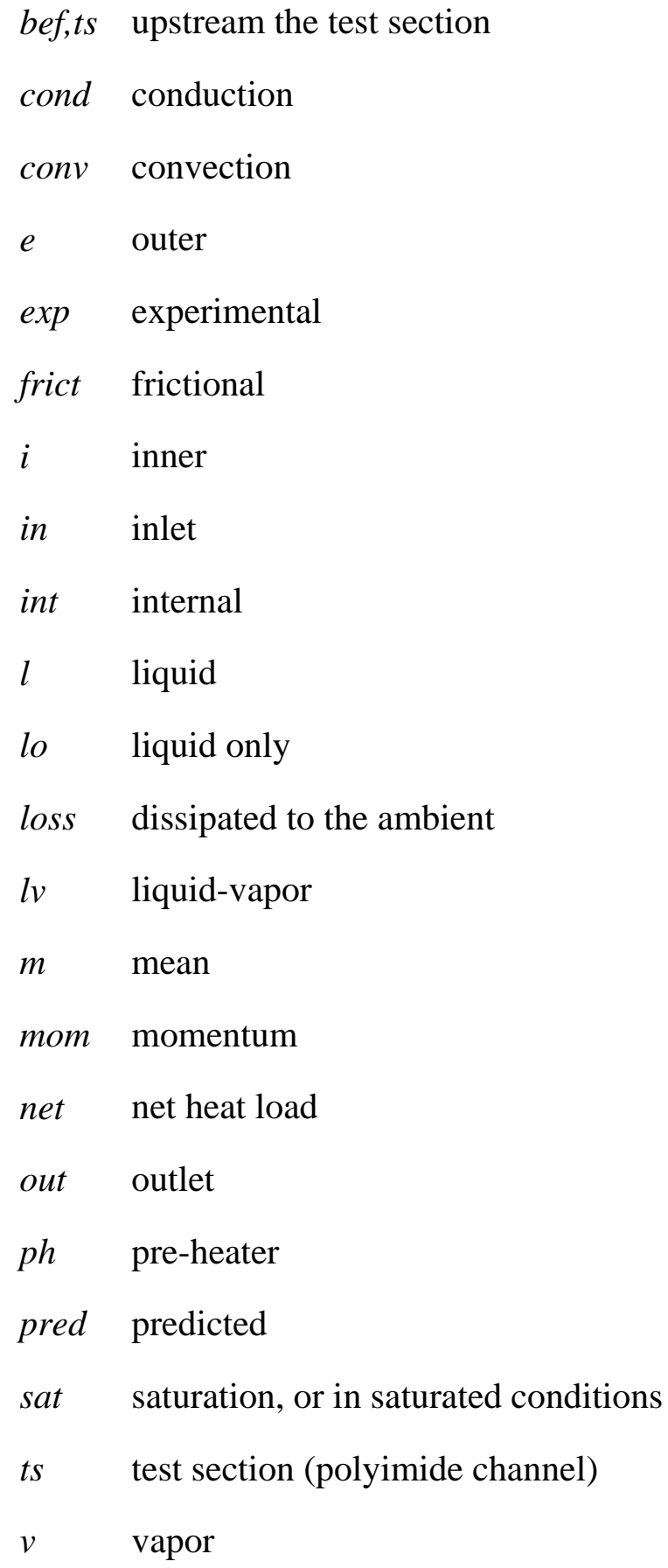

\section{Introduction and motivation}

Polymeric materials are usually ruled out of use for thermal and cooling devices in favor of metallic materials such as copper alloys, aluminum or stainless steel. However, a few specific applications require the use of plastic materials. In particular, the cooling system in the Upgrade of the ALICE Inner Tracking System (ITS) [1], to be 
commissioned at CERN in 2019, is expected to include lightweight circular cooling channels made of polyimide with the aim of minimizing the material pile-up within the detector sensitive area, essential for achieving higher detector resolution. In fact, even the boiling refrigerant itself circulating inside polyimide channels plays a role in this potential low weight solution for cooling this very large 12.5 Gigapixel detector, where the vapor fraction (average void fraction over 80\%) would minimize the material inventory compared to a liquid cooling system.

A literature survey revealed a lack of experimental data regarding flow boiling in polyimide channels. First, these channels are smoother than metallic channels used in industrial heat transfer applications. Fiorenza et al. [2] measured the statistical average roughness of surfaces in a polyimide heat sink using Atomic Force Microscopy (AFM), obtaining values ranging from 12 to $35 \mathrm{~nm}$, while smooth metallic channels are rougher, with values on the order of 100-1000 nm [3][4]. Wall roughness has been often reported to have an effect on the heat transfer coefficient. For instance, the three-zone model by Dupont, Thome and Jacobi [5] uses the measured surface roughness to set the dryout thickness and hence the onset and size of the dry zone with a substantial influence on its three-zone-averaged heat transfer coefficient. Furthermore, Karayiannis et al. [6] performed experimental studies on smooth and coarse minitubes. Heat transfer coefficients increased with heat flux for the coarse tube, while for the smooth tube the heat flux does not seem to have an influence. Smooth tubes would have fewer nucleation points and therefore convective boiling would dominate over a wider vapor quality spectrum. Also, most heat transfer coefficient prediction methods are based upon extensive experimental databases that typically do not include tests with plastic channels. In particular, the polyimide channel of interest here features very thin wall thickness (63 $\mu \mathrm{m}$ for a $2.689 \mathrm{~mm}$ internal diameter (ID) channel) and a very low thermal conductivity $\left(0.12 \mathrm{~W} \mathrm{~m}^{-1} \mathrm{~K}^{-1}[7]\right)$

Cooling channels in High Energy Physics (HEP) particle detectors display diameters usually below $4 \mathrm{~mm}$, mainly due to spatial and material inventory constraints. Different criteria predicting the transition from macro- to mini-/microchannels and channel categories were suggested by multiple authors. It is common to consider the macro- to minichannel transition happening at a diameter of $3 \mathrm{~mm}$, according to Bertsch et al. [8], Cheng et al. [9] and Kandlikar and Grande [10]. The biggest modules of the 
ALICE ITS Upgrade embed $2.667 \mathrm{~mm}$ ID polyimide channels [11], falling in the minichannel category, or in the micro- to macrochannel transition [12].

This study presents new experimental flow boiling results in a $2.689 \mathrm{~mm} \mathrm{ID}$ polyimide channel with a $285 \mathrm{~mm}$ heated length with $\mathrm{R} 245 \mathrm{fa}$ refrigerant as the evaporating fluid. The thermophysical properties of the fluid are summarized in Table 1. The experimental database comprises mass fluxes ranging from 100 to $500 \mathrm{~kg} \mathrm{~m}^{-2} \mathrm{~s}^{-1}$, heat fluxes from 15 to $55 \mathrm{~kW} \mathrm{~m}^{-2}$ and three saturation temperatures $\left(35,41\right.$ and $\left.47^{\circ} \mathrm{C}\right)$, while expanding the experimental flow boiling heat transfer database to another tube material and characteristics. The main goal is to understand the influence of key flow parameters (saturation temperature, mass flux and heat flux) on the boiling heat transfer coefficient, reported averaged along the polyimide channel. The experimental results are compared with data from similar experimental studies and predictive methods in the literature. Two-phase pressure drops and wall thermal resistance measurements are also evaluated. Besides adding the new test results to the literature and examining prediction methods, results are also aimed to provide insight into the ALICE ITS Upgrade cooling system.

\section{Experimental apparatus}

\subsection{Test rig}

The heated zone of the test setup, depicted in Figure 1, is made in two parts: a $2.3 \mathrm{~mm}$ ID, $496 \mathrm{~mm}$-long stainless steel pre-heater section, of which $396 \mathrm{~mm}$ are heated, and the effective test section, consisting of a single, circular, $2.689 \mathrm{~mm}$ ID polyimide channel, $300 \mathrm{~mm}$ long, where $285 \mathrm{~mm}$ are heated. The tube wall thickness is $63 \mu \mathrm{m}$, resulting in a $2.816 \mathrm{~mm}$ Outer Diameter (OD). The tube dimensions were carefully verified in a projection microscope from several tube samples.

After being pumped and its flow rate measured in a Coriolis-effect flow meter, the subcooled liquid R245fa refrigerant enters the first visualization section, a $2.1 \mathrm{~mm}$ ID quartz tube. A thermocouple immersed in the flow at the flange and a $0-400 \mathrm{kPa}$ pressure transducer provide temperature and absolute pressure experimental readings through which the enthalpy is determined. The fluid is heated at the pre-heater to the desired saturated condition at the polyimide channel entrance. A thermocouple placed at 
the stainless steel tube outer surface, $51 \mathrm{~mm}$ away from the preheater's second electrode, tracks the saturation temperature right before the entrance to the polyimide channel. The two-phase refrigerant enters the polyimide channel and is heated up by a counter-current water flow rate circulating in the annular gap between the channel and a larger glass tube, in a concentric heat exchanger fashion. This configuration was chosen because plastic channels cannot be electrically heated like metallic ones through the Joule effect.

Downstream of the polyimide channel, the refrigerant temperature is obtained with a thermocouple placed inside a hole in the brass outlet flange, $0.8 \mathrm{~mm}$ away from the internal wall. The refrigerant temperature is then again monitored using a similar technique as in the test section inlet. The differential pressure with respect to the inlet of the pre-heater is recorded thanks to a $0-300 \mathrm{kPa}$ differential pressure transducer. Finally, a second $2.1 \mathrm{~mm}$ ID visualization section made of quartz is used to record the flow with a 4000 FPS high-speed camera, before the refrigerant leaves the test rig on its way to the condenser and the refrigerant tank. By heating or cooling the tank using a secondary water-glycol loop, the operating pressure of the system can be adjusted.

All temperatures are measured using $0.25 \mathrm{~mm}$ type $\mathrm{K}$ thermocouples. When measuring wall temperatures, the thermocouples are attached tightly to the surface with plastic tape. Thermal paste is applied at the wall-thermocouple contact surface to ensure good thermal contact.

Concerning the heating water, a turbulent flow minimizes the convective thermal resistance with the polyimide tube outer wall. However, a high flow rate results in a lower water temperature decrease and thus a higher heat flux uncertainty, which would propagate to the boiling heat transfer coefficient. A compromise between these two requirements was found through a detailed parametric analysis determining the water flow characteristics that minimize the mean heat transfer coefficient uncertainty for the whole range of flow boiling conditions. To achieve this, the heating water should display:

1. Reynolds numbers from 3000 to 5500, which yield low convective thermal resistance between the heating water and the polyimide tube outer wall. 
2. Temperature differences from the water inlet to the outlet $\left(\Delta T_{\text {water }}\right)$ ranging from 0.9 to $2.5 \mathrm{~K}$, which provide acceptable heat flux uncertainty, as $\Delta T_{\text {water }}$ is the parameter contributing the most to it.

A $4.925 \mathrm{~mm}$ ID glass tube was chosen, resulting in an annular gap of $2.108 \mathrm{~mm}$. Water flow rates of $0.7-0.8 \mathrm{~L} \mathrm{~min}^{-1}$ and temperatures from 45 to $80^{\circ} \mathrm{C}$ guarantee the aforementioned conditions in the whole flow boiling experimental range. Finally, the glass tube is properly insulated, minimizing heat losses to the ambient. The pre-heater is well insulated too.

Fluid flows in the transitional regime are highly influenced by the inlet conditions. The water inlet manifold (see Figure 1) is designed in order to provide good mixing of the flow and ensure turbulent. Thermal stratification of the water should be avoided so as to guarantee uniform heat flux distribution in the polyimide channel periphery. The water flow and heat transfer in the annulus was simulated with Computational Fluid Dynamics (CFD) tools, assuming a constant boiling heat transfer coefficient in the refrigerant side as calculated for a specific flow boiling condition. Almost no thermal stratification of the water flow was observed in the whole test section length, with water temperatures differing by less than $0.1 \mathrm{~K}$ between the top and the bottom of the annular gap, as shown in Figure 2.

\subsection{Experimental facility}

The test rig is installed in the same experimental facility used and described in Tibiriçá and Ribatski [3] with the sole addition of a specific loop for circulating distilled water to heat the polyimide channel. The water loop is depicted in Figure 3. First, a thermal bath sets the water temperature. The fluid passes through a self-lubricating gear pump and then through a rotameter. Since the measured volumetric flow rate depends on the temperature of the fluid, the water temperature is tracked at the inlet and outlet of the rotameter. Two thermocouples are installed at the water inlet, right before the water starts heating the polyimide channel, and another two are located at the outlet. The temperature readings are double in order to decrease the water temperature difference uncertainty. No deviation higher than the sensor uncertainty was registered in the readings of the two pairs of thermocouples. 


\section{Experimental methodology}

\subsection{Heat flux}

The mean heat flux in the polyimide channel heated length $(L)$ is calculated as:

$$
q_{t s, m}=\frac{\dot{Q}_{n e t}}{\pi D_{i, t s} L}
$$

where $D_{i, t s}$ is the polyimide channel (test section) internal diameter, and $\dot{Q}_{n e t}$ is the net heat transfer rate from the heating water to the boiling R245fa. It is expressed as follows:

$$
\dot{Q}_{n e t}=\dot{Q}_{\text {water }}-\dot{Q}_{\text {loss }}
$$

$\dot{Q}_{l o s s}$ is the heat transfer rate to the ambient estimated by the free convection heat transfer correlation for a long horizontal cylinder by Churchill and Chu [13], considering the measured ambient temperature around the test section as the free stream temperature. Since the test section is well insulated, losses due to free convection constitute less than $5 \%$ of the total heat load. Radiative heat transfer losses are estimated to be even lower. $\dot{Q}_{\text {water }}$ is computed as follows:

$$
\dot{Q}_{\text {water }}=\dot{m}_{\text {water }} c_{p, \text { water }} \Delta T_{\text {water }}
$$

where $\dot{m}_{\text {water }}$ is the water mass flow rate, and $\Delta T_{\text {water }}$ is the water temperature decrease.

Matkovic et al. [14] used water as the cooling agent in their experimental condensation studies, calculating local heat fluxes by fitting water temperature measurements of the water stream along the test section by a second order polynomial and applying an energy balance. Such strategy was considered in the present study, but was abandoned as it results in high uncertainty and complexity: it was estimated that 12 or more water temperature readings were needed along the annulus to provide acceptable, low error results. At the same time it was proven that, given the short length of the heated channel and high water flow rates, little heat flux variation happens along the test section. Hence, using the average heat flux was found to be the best approach. 


\subsection{Heat transfer coefficient}

The primary result in the present study is the boiling heat transfer coefficient averaged along the whole polyimide channel length. Most of the recent similar experimental works report local heat transfer coefficient values by measuring the tube wall temperature locally, but such measurements proved to be unreliable in the present polyimide channel setup. The sensors have to be physically separated from the heating water flow by encapsulating them, adding an extra thermal resistance in this operation which decreases the local heat flux. This, combined with low conductive heat transfer rate in the channel wall due to the low thermal conductivity of polyimide, resulted in lower local wall temperatures than in naked sections of the channel. Likewise, good thermal contact between the thermocouples and the channel surface, lacking rigidity and adherence, was not guaranteed. These obstacles discouraged a local approach to the results.

The global resistance to heat flow from the heating water to the boiling R245fa may be expressed using average thermal resistances, as follows:

$$
R_{\text {global }}=R_{\text {conv, ann }}+R_{\text {condwall }}+R_{\text {convint }}
$$

The three thermal resistances above are calculated using the following equations:

$$
\begin{aligned}
& R_{\text {conv }, a n n}=\frac{T_{\text {water }, m}-T_{\text {wall }, \text { st, },}}{\dot{Q}_{\text {net }}} \\
& R_{\text {cond }, \text { wall }}=\frac{T_{\text {wall,ts,e }}-T_{\text {wall }, t, i}}{\dot{Q}_{\text {net }}} \\
& R_{c o n v, \text { int }}=\frac{T_{\text {wall,ts,i }}-T_{R 245 f a, m}}{\dot{Q}_{n e t}}
\end{aligned}
$$

All temperatures in Equations $(5,6,7)$ are referred to mean values. $T_{\text {wall,ts,e }}$ and $T_{\text {wall,ts,i}}$ are the polyimide channel external and internal mean temperatures, respectively. $T_{\text {water, } m}$ and $T_{R 245 f a, m}$ are the mean temperatures of the water flow and the R245fa refrigerant. 
The thermal resistance of conduction across the polyimide tube wall $\left(R_{\text {cond,wall }}\right)$ is determined as described in section 3.4.1. A validated, single-phase heat transfer correlation provides the convection thermal resistance from the heating water to the outer polyimide channel wall $\left(R_{\text {conv,ann }}\right)$ following the procedure discussed more in detail in section 3.4.2. $R_{\text {conv,int }}$ is the sought convective thermal resistance between the polyimide tube inner wall and the refrigerant. It can be calculated by combining the equations above, resulting in the following expression:

$R_{\text {conv,int }}=\frac{T_{\text {water }, m}-T_{R 245 f a, m}}{\dot{Q}_{\text {net }}}-R_{\text {conv }, a n n}-R_{\text {cond,wall }}$

Finally, the mean two-phase flow boiling heat transfer coefficient inside the polyimide channel, $h_{t s, m}$, is calculated as:

$$
h_{t s, m}=\frac{1}{R_{c o n v, i n t}\left(\pi L D_{i, t s}\right)}
$$

\subsection{Vapor quality}

The vapor quality is expressed averaged along the polyimide channel (test section) considering vapor qualities at its inlet and outlet:

$$
x_{t s, m}=\frac{x_{t s, \text { in }}+x_{t s, \text { out }}}{2}
$$

Assuming that thermodynamic equilibrium is achieved in steady-state conditions, the thermodynamic vapor quality at the polyimide channel inlet, $x_{t s, i n}$, is calculated as follows:

$x_{t, \text { in }}=\frac{\left(\frac{\dot{Q}_{p h}}{G_{p h} A_{i, p h}}+i_{p h, i n}\right)-i_{l, t s, i n}}{i_{l v, t s, i n}}$

$\dot{Q}_{p h}$ is the electric power provided to the pre-heater; $G_{p h}$ and $A_{i, p h}$ are the mass flux and the internal cross section in the pre-heater. $i_{l, t s, i n}$ and $i_{l, t s, i n}$ are the liquid and vaporization 
enthalpies at the polyimide channel entrance. These two parameters are calculated from the saturation pressure at the polyimide tube inlet, which is determined from the saturation pressure at the pre-heater outlet minus a singular pressure drop at the inlet (see section 3.6).

The vapor quality at the polyimide channel outlet is expressed below:

$x_{t s, \text { out }}=\frac{\left(\frac{\dot{Q}_{p h}}{G_{p h} A_{i, p h}}+\frac{\dot{Q}_{n e t}}{G_{t s} A_{i, t s}}+i_{p h, \text { in }}\right)-i_{l, t s, \text { out }}}{i_{l v, \text { ts out }}}$

$G_{t s}$ and $A_{i, t s}$ are the mass flux and the internal cross section in the polyimide channel. $i_{l, t s, \text { out }}$ and $i_{l v, t s, \text { out }}$ are the liquid and vaporization enthalpies at the polyimide channel outlet, calculated from the measured outlet saturation pressure after accounting for the singular two-phase pressure drop in the outlet flange determined beforehand (see section 3.6).

\subsection{Water-water tests}

Tests with two streams of water in counter-current (i.e. in the annular space and inside the polyimide channel) were conducted with two goals: experimentally measure $R_{c o n d, w a l l}$, and validate the use of empirical correlations to determine $R_{c o n v, a n n}$. These two thermal resistances are required to calculate $R_{\text {conv, int }}$ in Equation ( 8 ) and, subsequently the mean heat transfer coefficient in the polyimide channel in Equation ( 9 ) during the two-phase flow boiling tests.

\subsubsection{Thermal resistance of conduction across the tube wall}

A steady-state, 1-D thermal conduction analysis across the tube wall using cylindrical coordinates results, applying Fourier's law of thermal conduction, in a logarithmic temperature distribution [15]. The thermal resistance of conduction across the tube wall can be expressed as follows: 
$R_{\text {cond,wall }}=\frac{\ln \left(\frac{D_{e, t s}}{D_{i, t s}}\right)}{2 \pi k_{t s} L_{\text {heated }}}$

where $k_{t s}$ is the thermal conductivity of the channel wall. In practice, when considering the dimensional tolerances of $D_{e, t s}$ and $D_{i, t s}$, Equation ( 9 ) yields high uncertainty. This is due to the low thermal conductivity of the polyimide channel: $0.12 \mathrm{~W} \mathrm{~m}^{-1} \mathrm{~K}^{-1}$ [7], more than 130 times lower than stainless steel. Error propagation in Equation ( 9 ) may result in heat transfer coefficient uncertainties often exceeding $100 \%$.

A series of water-water tests were carried out with the aim of determining experimentally the thermal resistance across the polyimide tube wall in the channel later used in the flow boiling heat transfer tests, using neither the channel dimensions nor its thermal conductivity. The test strategy is the following:

1. Set a highly turbulent water flow rate inside the polyimide channel $\left(R e_{i n t}>\right.$ 20000) at a fixed temperature.

2. Set a counter-current water flow rate in the annulus to a fixed temperature, significantly higher than the internal flow.

3. Gradually increase the annulus water flow rate from $R e_{a n n}=3000$ to the maximum value possible.

The global thermal resistance between the two water flows can be expressed as in Equation ( 4 ). Since the internal flow rate is fixed and turbulent, the convective thermal resistance $\left(R_{\text {conv,int }}\right)$ can be accurately calculated using a single-phase, forced convection heat transfer coefficient correlation from the literature for the turbulent flow regime in circular channels. The correlation for circular channels by Gnielinski [16] as described in the VDI Atlas [17] was chosen. The convective thermal resistance between the water in the annulus and the polyimide channel outer wall $\left(R_{c o n v, a n n}\right)$ will depend on the variable mass flow rate in the annulus. Considering an infinitely high water flow rate $\left(R e_{a n n} \rightarrow \infty\right), R_{\text {conv, ann }}$ converges to zero. In such conditions, and taking into account $R_{\text {cond,wall }}$ is a constant, the global thermal resistance expressed in Equation ( 4 ) remains as the sum of two constant thermal resistances, $R_{\text {cond,wall }}$ and $R_{\text {conv, int }}$.

An expression of $R_{\text {global }}$ fulfilling the conditions stated above is the following: 
$R_{\text {global }}=\left(R_{\text {conv }, \text { int }}+K_{1}\right) e^{\left(\frac{K_{2}}{\mathrm{Re}_{a n n}}\right)}$

As $R_{\text {global }}$ is calculated using the $\varepsilon$-NTU method for concentric, counter-current heat exchangers [18], and $R_{\text {conv, int }}$ is known, the experimental data can be fitted using the unweighted least squares method to match Equation ( 14 ) by tuning the values of the $K_{l}$ and $K_{2}$ constants. $K_{1}$ is the ultimately sought $R_{\text {cond,wall }}$ value.

Figure 4 shows the experimental thermal resistance values versus $R e_{a n n}$ for a case where the annulus water stream is at $50^{\circ} \mathrm{C}$ and the water inside the tube is at $20^{\circ} \mathrm{C}$. $R_{\text {global }}$ is fitted according to Equation ( 14 ), with $R_{\text {conv, int }}=0.012 \mathrm{~K} \mathrm{~W}^{-1}$ as calculated using the Gnielinski correlation [16]. A value of $R_{\text {cond,wall }}=0.095 \mathrm{~K} \mathrm{~W}^{-1}$ is obtained. The same procedure was repeated for different water flow and temperature conditions, resulting in an average $R_{\text {cond,wall }}$ value of $0.0924 \pm 0.0087 \mathrm{~K} \mathrm{~W}^{-1}$ as reported in Table 2 .

The sole heat transfer coefficient correlation used when calculating $R_{\text {cond,wall }}$ was the one to determine $h_{t s, m}$ and ultimately $R_{\text {conv, int }}$. Furthermore, all tests were performed at $R_{\text {conv, int }}<0.1 \cdot R_{\text {global }}$, in order to minimize its influence in the fit and hence obtain accurate $R_{\text {cond,wall }}$ results.

\subsubsection{Validation of the heat transfer coefficient correlation in the annulus}

Once $R_{\text {cond,wall }}$ is determined, the experimental value of $R_{\text {conv, ann }}$ may be obtained through Equation ( 4 ) and compared to values given by single-phase, forced convection heat transfer coefficient correlations in the annulus. The following four correlations were considered: the correlations for circular channels by Gnielinksi [16], Petukhov [19] and Dittus-Boelter [20], and Gnielinski's specific correlation for the cylindrical annulus geometry described in the VDI Atlas [21]. In the first three correlations, the characteristic dimension is the hydraulic diameter of the annulus. The deviation between the values given by the correlations and the experimental thermal resistances is expressed using the Mean Relative Error (MRE) and the Mean Absolute Error $(M A E)$, calculated according to the equations below:

$M R E=\frac{1}{n} \sum_{i=1}^{n} \frac{X_{p r e d}-X_{\exp }}{X_{\exp }} 100[\%]$ 
$M A E=\frac{1}{n} \sum_{i=1}^{n}\left|\frac{X_{\text {pred }}-X_{\text {exp }}}{X_{\text {exp }}}\right| 100[\%]$

where $X$ is $R_{\text {conv,ann }}$, in this case.

Table 3 reports the $M A E$ for several water-water cases, as well as a water-singlephase R245fa case in the last row. It is observed that the correlation by Petukhov [19] and its version for low Reynolds numbers by Gnielinski [16] provide the minimum $M A E$, being the Petukhov correlation the best overall fit. The use of this correlation for calculating $R_{\text {conv,ann }}$ in two-phase flow conditions is justified and will yield fairly accurate results.

\subsection{Single-phase flow validation tests}

A series of single-phase R245fa tests were performed with the aim of validating the experimental setup. First, single-phase adiabatic tests were conducted. In order to keep adiabatic conditions in the polyimide tube, a low water flow rate was established (laminar flow regime) and its temperature set equal to the average temperature of the single-phase R245fa refrigerant, so negligible water temperature changes were recorded. Measured single-phase R245fa pressure drop values in adiabatic conditions were compared to the frictional pressure drop correlations by Churchill [22] and Gnielinski [16], as illustrated in Figure 5. An excellent match was observed, especially with the correlation by Churchill.

Diabatic single-phase tests were conducted with a dual purpose: performing energy balances, and assessing the effective uncertainty of the heat transfer coefficient inside the polyimide tube. Energy balances are of key importance to ensure accurate vapor quality estimates and quantify the effective heat transfer rate to the refrigerant. To do these tests, the pre-heater was powered, while the polyimide tube was kept in adiabatic conditions by applying the strategy described above. The energy balance in the pre-heater only, using the temperature difference between the inlet and the value measured by the thermocouple before the polyimide channel $\left(\Delta T_{\text {in-bef,ts }}\right)$, is calculated as follows: 
$\left[\frac{\Delta \dot{Q}}{\dot{Q}}\right]_{p h}=\frac{\dot{m}_{R 245 f a} c_{p, R 245 f a} \Delta T_{i n-b e f, t s}-\dot{Q}_{p h}}{\dot{Q}_{p h}} 100[\%]$

The energy balance in the pre-heater is plotted in Figure 6 (a), showing deviations within $15 \%$ for $R e_{p h}>2000$. A second diabatic test was performed, keeping the pre-heater off and heating with water the single-phase R245fa refrigerant at the polyimide channel only. In this case, the energy balance consists in comparing the net heat load provided by the heating water $\left(\dot{Q}_{n e t}\right)$, computed according to Equations ( 2, 3 ), and the total power received by the $\mathrm{R} 245 \mathrm{fa}\left(\dot{Q}_{R 245 f a}\right)$, as follows:

$\left[\frac{\Delta \dot{Q}}{\dot{Q}}\right]_{t s}=\frac{\dot{Q}_{n e t}-\dot{Q}_{R 245 f a}}{\dot{Q}_{R 245 f a}} 100[\%]$

where $\dot{Q}_{R 245 f a}$ is calculated using the expression below:

$\dot{Q}_{R 245 f a}=\dot{m}_{R 245 f a} c_{p, R 245 f a} \Delta T_{\text {in-out }}$

where $\Delta T_{\text {in-out }}$ is the temperature difference between the test rig inlet and outlet, measured by the thermocouples immersed in the R245fa flow. Figure 6 (b) displays energy balance in the polyimide channel. Deviations around $-10 \%$ are reported at $R e_{t s}>$ 2000. Given the accuracy expected in the experimental setup, these results are considered acceptable.

The single-phase heat transfer coefficient in the polyimide tube was assessed as an additional validation of the setup. The procedure consists in calculating, first, $R_{\text {global }}$ according to the $\varepsilon$-NTU method for concentric, counter-current heat exchangers [15] with $\dot{Q}_{R 245 f a}$ as input. By then introducing $R_{\text {cond,wall }}=0.0924 \mathrm{~K} \mathrm{~W}^{-1}$ and determining $R_{\text {conv, ann }}$ through the validated correlation by Petukhov [19], $R_{\text {conv, int, }}$ and subsequently the values of $h_{t s, m}$, are calculated, as described in Equations $(8,9)$. The values of $h_{t s, m}$ obtained using the R245fa stream are very accurate, thanks to the low uncertainty of $\dot{Q}_{R 245 f a}$, and thus are considered in the scatter plot in Figure 7 as the benchmark heat transfer coefficients ( $X$-axis, $\left.h_{\text {exp }}\right)$. In the $Y$-axis, $h_{\text {pred }}$ can be determined in two ways:

1. Experimentally as $h_{t s, m}$, using the heat load as calculated from the water stream by repeating the method above using $\dot{Q}_{n e t}$ instead of $\dot{Q}_{R 245 f a}$, as it will 
be done in the two-phase flow boiling tests. This involves a higher error due to the higher uncertainties of the instrumentation in the heating water circuit.

2. Theoretically, from the correlations by Churchill [22] and Gnielinski [16].

Results are brought into comparison in Figure 7. $h_{\text {pred }}$, calculated as by the two approaches above, falls well within a $\pm 30 \%$ deviation range with respect to the reference heat transfer coefficients estimated from $\dot{Q}_{R 245 f a},\left(h_{\text {exp }}\right)$, except at the bottom of the scale, where higher uncertainties were observed.

\subsection{Singular pressure drop evaluation}

Two-phase flow tests in adiabatic conditions at the polyimide channel provide a way to obtain the singular two-phase pressure drops. They were observed after comparing the experimental and the total theoretical pressure drop values, expressed as follows:

$$
\Delta p_{\text {total,theory }}=\Delta p_{\text {frict }}+\Delta p_{\text {mom }}
$$

where $\Delta p_{\text {frict }}$ is the two-phase frictional pressure drop component. Multiple methods from literature were considered for the calculation of this component: MüllerSteinhagen and Heck [23], Friedel [24], Da Silva and Ribatski [25], and SempérteguiTapia and Ribatski [26].

$\Delta p_{\text {mom }}$ is the momentum pressure gradient. For separated and disperse flows in saturated conditions, in a circular channel of uniform diameter, it is calculated with the following equation, according to Collier and Thome [27]:

$$
\Delta p_{\text {mom }}=G^{2}\left\{\left[\frac{(1-x)^{2}}{(1-\varepsilon) \rho_{l}}+\frac{x^{2}}{\varepsilon \rho_{v}}\right]_{\text {out }}-\left[\frac{(1-x)^{2}}{(1-\varepsilon) \rho_{l}}+\frac{x^{2}}{\varepsilon \rho_{v}}\right]_{\text {in }}\right\}
$$

where $\varepsilon$ is the void fraction, calculated in this study using Steiner's version [28] of the drift flux void fraction correlation by Rouhani and Axelsson [29]. No gravity component is included, as the system is horizontal. Figure 8 reports the deviation between the experimental and the theoretical two-phase pressure drop using the Müller- 
Steinhagen and Heck correlation [23] for the frictional component. The difference between the two is attributed to the pressure drop in the singularities.

According to the local saturation temperature drops recorded by the thermocouples before and after the polyimide channel, singular pressure drops are localized at the connections to the pre-heater and to the outlet flange. Indeed, the diameter changes before the polyimide tube, from the $2.3 \mathrm{~mm}$ ID preheater tube to the $2.689 \mathrm{~mm}$ ID of the polyimide channel, and vice versa at the outlet. Assuming the difference between the theoretical and experimental two-phase pressure drops is entirely due to singularities, the following expression can be used:

$\Delta p_{\text {sing }}=\Delta p_{\exp }-\Delta p_{\text {total, theory }}$

In order to determine $\Delta p_{\text {sing }}$, the use of a frictional pressure drop model should be validated. To do so, the procedure below was followed:

1. Run two-phase flow cases with adiabatic conditions in the polyimide channel for several mass fluxes and vapor qualities. For each run, calculate the $\Delta p_{\text {sing }}$ values using different correlations for the frictional pressure drop component: Müller-Steinhagen and Heck [23], Friedel [24], Da Silva and Ribatski [25], and Sempértegui-Tapia and Ribatski [26], and Equations ( 20 $22)$.

2. Run identical cases (i.e. identical vapor quality at the polyimide channel entrance), but heating the polyimide tube with the heating water. $\Delta p_{\text {total,theory }}$ can be determined by entering the values of $\Delta p_{\text {sing }}$ calculated previously in the adiabatic cases for each two-phase frictional pressure drop model, as described above, plus the momentum pressure gradients using Equation ( 21 ) .

3. Compare the experimental and the theoretical two-phase pressure drops calculated in steps 1 and 2, choosing the frictional two-phase pressure drop model providing the minimum deviation.

This validation method assumes $\Delta p_{\text {sing, in }}=\Delta p_{\text {sing,out }}$, even if $x_{t s, \text { out }}>x_{t s, \text { in }}$ in the diabatic test runs. How the singular pressure drop is distributed between the inlet and the outlet of the polyimide channel is uncertain, as there are small plenums at the 
connections of both ends of the polyimide channel with the two-phase circuit. A sensitivity check was performed on the experimental two-phase diabatic test data recorded at step 2 above. It consists in altering the location of the singular pressure drop, placing it either entirely at the channel inlet or the outlet. After recalculating the mean vapor quality and the heat transfer coefficient, the observed changes are several times lower than the uncertainty of the two parameters. Thus, it can be assumed that the singular pressure drop localized at the two ends of the polyimide channel is equally distributed between the inlet and the outlet. Also, the small vapor quality increases experienced in the diabatic tests have little influence on the variations of $\Delta p_{\text {sing,in }}$.

Table 4 summarizes the $M R E$ and $M A E$, as expressed in Equations ( 15, 16 ), of the predicted two-phase pressure drop values $\left(\Delta p_{\text {total,theory }}\right)$, calculated using each of the four two-phase frictional pressure drop correlations, versus the experimental pressure drop $\left(\Delta p_{\text {exp }}\right)$, for the entire experimental database, nearly 300 points. The fraction of data predicted within the $\pm 20 \%$ error band is also indicated $\left(\lambda_{20 \%}\right)$. It can be concluded that the two-phase frictional pressure drop correlations by Müller-Steinhagen and Heck [23] and Sempértegui-Tapia and Ribatski [26] provide the best accuracy in determining $\Delta p_{\text {sing. }}$. The method by Müller-Steinhagen and Heck [23] was finally chosen, since the method by Sempértegui-Tapia and Ribatski yields higher propagated uncertainties in the current setup. A visual example of the comparison between the theoretical and experimental total pressure drops can be found in Figure 9.

Once $\Delta p_{\text {sing,in }}$ is determined for each of the two-phase flow boiling tests, the saturation temperature at the inlet of the polyimide channel can be estimated. First, a 3equation system is solved in the pre-heater section, involving the subcooled liquid energy balance, the liquid pressure drop (using the Gnielinski correlation for calculating the friction factor [16]), and the equation of state relating $T_{\text {sat }}$ and $p_{\text {sat }}$. The result is the saturation temperature in the pre-heater at $x=0$. Equation ( 20 ) yields the pressure drop in the pre-heater saturated region. The saturation pressure at the polyimide channel inlet is determined by subtracting $\Delta p_{\text {sing, in }}$ from the saturation pressure at the pre-heater tube end. 


\subsection{Calibration and error analysis}

All temperature measurements were recorded using $0.25 \mathrm{~mm}$ type $\mathrm{K}$ thermocouples, calibrated here to the $23-79^{\circ} \mathrm{C}$ range following the method by Abernethy and Thompson [30], and their uncertainty determined as recommended by NIST standards [31]. The water rotameter was calibrated at $40,50,60,70$ and $80^{\circ} \mathrm{C}$, since the readings of the volumetric flow rate depend on the flow density and viscosity. Double linear interpolations were utilized for intermediate temperature and flow values. A factory-cut section of the same polyimide channel used in the tests was measured in a projection microscope to verify the diameter dimensions and the tolerances.

The uncertainties in derived parameters were propagated using the method by Kline and McClintock [32]. Prior to data acquisition, the experimental system was always allowed to achieve steady-state conditions. For each experimental point, the standard deviations of all measurements in time were calculated and verified that their values did not exceed $10 \%$ of the uncertainty of the instrument.

Table 5 indicates the uncertainty of the measured variables. The uncertainties in the calculated variables highly depend on the experimental conditions. Generally, the uncertainty in the mean heat transfer coefficient ranges between 13 to $39 \%$, with a global average value of $21 \%$. Only heat transfer coefficient values with uncertainties below $35 \%$ are considered in this study. The average uncertainty of the mean vapor quality in the test section is $4 \%$.

Repeatability tests were performed to ensure stability of the facility. The plot in Figure 10 shows the two-phase heat transfer coefficient results of two tests with identical conditions performed on different days, with no significant deviation observed in the mean heat transfer coefficient values. Instabilities in the form of liquid fronts moving at higher speed than the two-phase flow were observed in the high-speed flow images under certain experimental conditions. Sempértegui-Tapia et al. [33] used the present experimental facilities for his studies, acknowledging instabilities of the same nature. Such instabilities increase the liquid entrainment in the flow. In the present study they were almost completely mitigated by adjusting the needle valve upstream the experimental section, although there were certain cases where it was not possible to eliminate them entirely and the measurements were not considered. All the experimental results in this paper are taken in stable boiling conditions. 


\section{Experimental results}

Flow boiling tests were run for R245fa refrigerant at three mean saturation temperatures in the polyimide channel $\left(35,41\right.$ and $\left.47^{\circ} \mathrm{C}\right)$ for mass fluxes ranging from 100 to $500 \mathrm{~kg} \mathrm{~m}^{-2} \mathrm{~s}^{-1}$, heat fluxes from 15 to $55 \mathrm{~kW} \mathrm{~m}^{-2}$, and vapor qualities between 0.05 and 0.80 . Results of the average heat transfer coefficients in the polyimide channel, as indicated in Equation ( 9 ), were analyzed parametrically and their trends compared to those provided by prediction methods and similar experimental studies in the literature.

Stratification of the flow was observed at low vapor qualities, as shown in Figure 11. As flow visualization was performed at the $2.1 \mathrm{~mm}$ ID quartz tube at the end of the test section, it can be deduced that, if flow stratification is observed here, such an effect occurs in the larger polyimide tube too. Indeed, the Confinement number $(\mathrm{Co})$ is 0.37 in the polyimide channel at the lowest saturation temperature in the tests. Applying the macro- to microscale transition criterion by Kew and Cornwell [34], (Co > 0.5 for microchannels), the two-phase flow boiling in the polyimide channel falls in the macroscale region, where gravitational effects dominate over surface tension forces and flow stratification occurs. The transition criterion by Ong and Thome [35], mainly depending upon the uniformity of the liquid film thickness in the channel perimeter, establishes that $C o$ values between 0.3 and 1 correspond to a transitional regime (mesoscale), smoothly shifting from macroscale ( $C o<0.3)$ to microscale regime ( $C o>$ 1). Thus, the two-phase flows in the polyimide channel dwell in a transitional regime between macroscale and microscale. Also, other studies using R245fa reported stratified flows for channels larger than $2 \mathrm{~mm}$ ID [36].

Dryout conditions were difficult to capture with the existing instrumentation and methodology, since mean heat transfer coefficients and vapor qualities were studied, and the tests involve low vapor quality increases in the polyimide channel. Figure 12 shows a slight heat transfer coefficient drop at high vapor qualities for $G=100 \mathrm{~kg} \mathrm{~m}^{-2} \mathrm{~s}^{-}$ ${ }^{1}$, which suggests partial dryout conditions, while the high-speed images certainly confirm liquid film evaporation from the tube wall. 


\subsection{Parametric analysis of the results}

\subsubsection{Influence of the mass flux}

The flow boiling heat transfer coefficient increases with increasing mass velocity for fixed heat flux and saturation temperature conditions, as shown in Figure 12. This effect is stronger at higher vapor qualities and mass flux values between 200 and $300 \mathrm{~kg} \mathrm{~m}^{-2} \mathrm{~s}^{-1}$. In general, similar experimental studies and heat transfer coefficient correlations and models report this behavior. The saturation temperature has also an impact on the magnitude of the influence of the mass flux: as reported in Figure 13, the heat transfer coefficient increasing with increasing mass flux is mildly amplified at lower saturation temperatures. Last, by comparing Figure 12 (a) and Figure 13 (b), it can be seen that the effect is more intense at lower heat fluxes. In any case, the heat transfer coefficient increases with increasing vapor qualities in a rather linear fashion, after a small plateau at low vapor qualities, only observed at low mass and heat fluxes.

\subsubsection{Influence of the heat flux}

No relevant heat transfer coefficient dependence on the heat flux was observed. According to the plot in Figure 14 (a), the heat transfer coefficient does not increase when shifting $q_{t s, m}$ from 15 to $25 \mathrm{~kW} \mathrm{~m}^{-2}$. At heat fluxes from 5 to $15 \mathrm{~kW} \mathrm{~m}^{-2}$, the heat transfer coefficient seems to increase slightly within the uncertainty range with increasing heat flux (not shown in Figure 14).

It is emphasized that, for a fixed mass flux and different heat fluxes, the vapor quality difference from the polyimide channel inlet to the outlet is higher at higher heat fluxes. Therefore, quantifying the influence of the heat flux on the average heat transfer coefficient values by directly comparing different cases might be misleading. For instance, in Figure 14 (a), the vapor quality increase in the polyimide channel $\left(\Delta x_{\text {in-out }}\right)$ is 0.18 at $15 \mathrm{~kW} \mathrm{~m}^{-2}$ and 0.30 at $25 \mathrm{~kW} \mathrm{~m}^{-2}$. Thus, the two experimental conditions cannot be fairly compared directly. This effect is illustrated in Figure 14 (b), where the mean heat transfer coefficient in the polyimide channel is plotted versus the inlet and outlet vapor qualities, instead of the mean values. However, it can be seen that, in the cases considered, the heat transfer coefficient does not significantly increase with the 
heat flux; otherwise, the $25 \mathrm{~kW} \mathrm{~m}$ m $^{-2}$ curve would be shifted towards the left of the plot in Figure 14 (a).

If the heat transfer coefficient increasing effect with the heat flux is only slightly noticeable but not significant at low mass flux and low vapor qualities, it disappears at higher mass fluxes, as it can be observed by comparing Figure 14 (a) and Figure 15. In these plots, it can be seen that at low vapor qualities, the heat transfer coefficients tend to be slightly lower at the lower heat fluxes whilst at $47^{\circ} \mathrm{C}$ (not displayed in Figure 15), the same behaviors were observed.

Since the smooth tube surface would not provide many potential nucleation sites, and the polyimide channel is relatively long (thus heat fluxes are not very high), convective boiling is expecting to dominate over nucleate boiling. Furthermore, convective boiling effects are enhanced with the R245fa refrigerant, due to its high specific vapor volume. As a result, no dependence of the heat flux on the heat transfer coefficient is observed. Such a behavior is opposite to the low vapor quality flow boiling results obtained by Tibiriçá and Ribatski [3] at the same experimental apparatus with the same fluid (R245fa) in a stainless steel channel of similar inner diameter, confirming that the material and surface smoothness of the channel do in fact influence the flow boiling heat transfer characteristics.

\subsubsection{Influence of the saturation temperature}

In general, two trends were identified:

a) At low mass and heat fluxes, the mean heat transfer coefficient depends weakly on the saturation temperature, increasing slightly for higher temperatures, as reported in Figure 16 (a).

b) At higher mass and heat fluxes, the mean heat transfer coefficient shows the opposite trend: it decreases when increasing the saturation temperature, as shown in Figure 16 (b) illustrates this trend.

Trend (b) is related to the decrease of the vapor specific volume at higher temperatures (see Table 1), which reduces convective effects, decreasing the heat transfer coefficient. The decrease of the liquid thermal conductivity might be 
contributing to the falling of the heat transfer coefficient. In comparison, studies from the literature using metallic channels [3] report that the heat transfer coefficient increases with increasing saturation temperatures, especially at low mass flux and low vapor qualities. Increasing the temperature (or pressure) of the fluid in those studies decreased its surface tension, resulting in lower bubble departure diameters. The result is a higher density of nucleation sites and intensification of nucleate boiling. These effects almost disappear at high mass flux and vapor qualities, where convective effects dominate. As no heat transfer intensification was observed in the present experimental tests upon increasing the fluid saturation temperature, it may be concluded that nucleate boiling does not become an important mechanism.

\subsection{Comparison with experimental results from similar studies}

Figure 17 (a) presents experimental data obtained by Tibiriçá and Ribatski [3] and Kanizawa et al [37] in a $2.32 \mathrm{~mm}$ ID channel with R245fa refrigerant, compared to results from the present work. Also, the heat transfer coefficient dependence on the heat flux was studied by Kanizawa et al. [37], observing increasing values for increasing heat fluxes at low vapor qualities, whereas this effect disappears at higher qualities, as illustrated in Figure 17 (b). The authors attributed this behavior to nucleate boiling effects dominating at $x<0.4$, with convective evaporation taking over at higher qualities. Such effects were not observed in the present study, indicating again the dominance of convective boiling in the polyimide channel. The heat transfer coefficient trends with vapor quality were reproduced.

Studies in metallic channels have also reported heat transfer coefficient drops with increasing vapor quality at low vapor qualities and high heat fluxes, as displayed in Figure 17 (b) at 35 and $45 \mathrm{~kW} \mathrm{~m}^{-2}$. This effect is related to nucleate boiling suppression effects [35] and to bubble coalescence processes [37]. No heat transfer coefficient drops were observed in the present study, since mean heat transfer coefficients and vapor qualities were reported along the test section instead of local values. Besides, the weak nucleate boiling effects in the polyimide channel will not give rise to a heat transfer coefficient dependence on the heat flux. 


\subsection{Comparison with heat transfer prediction models.}

A comparison between the experimental data and four flow boiling heat transfer prediction methods [37]-[40] was conducted with the aim of evaluating their ability to predict the present flow boiling experimental data recorded in the polyimide channel. The predictive methods are compared to the experimental data, using the mean absolute and relative error, $(M A E, M R E)$, as defined in Equations ( 16, 15$)$, and the fraction of data predicted within the $\pm 30 \%$ error band, $\lambda_{30 \%}$. Table 6 summarizes the statistical comparison of the methods with the present full experimental database (top rows) and with the experimental points displaying heat transfer coefficient uncertainties lower than $\pm 35 \%$ (bottom rows).

The annular flow suite by Cioncolini and Thome [38] is a purely convective approach, capturing the intensification of the convective effects in smooth tubes. According to Table 6, it predicts more than $80 \%$ of the experimental results within a $\pm 30 \%$ error band, if considering only the experimental data with uncertainty below $\pm 35 \%$. Besides, it presents low MAE and MRE. This method is based upon an algebraic turbulence model for annular flows, the flow pattern of most of the two-phase experimental conditions tested as recorded in the high-speed images, and it is the only one of the four methods that does not take into consideration the influence of the heat flux. This was precisely an effect observed in the entire experimental database. Additionally, this model reproduces the parametric effects of the mass flux, the saturation temperature, and, especially, the vapor quality on the heat transfer coefficient.

The method by Liu and Winterton [39], originally developed for channels larger than $3 \mathrm{~mm}$ ID, is the second best from the four considered, although it barely predicts $50 \%$ of the entire experimental database with a $\pm 30 \%$ error. The average errors with respect to the experimental database are also high. However, it provides qualitative predictions of the experimental mean heat transfer coefficients dependence on mass flux and saturation temperature. On the other hand, the method tends to significantly overestimate heat transfer coefficients at low vapor qualities, as it accounts for nucleate boiling effects. This behavior was not observed in the experimental results.

Kandlikar and Balasubramanian [40] proposed a heat transfer coefficient correlation for flow boiling in the micro- and minichannel range. They put forward different expressions depending on the value of the liquid-only Reynolds number $\left(\operatorname{Re}_{l o}\right)$ : 
$R e_{l o}>3000$ (large diameter tubes), $1600<R e_{l o}<3000$ (laminar, transition flow region in minichannels) and $R e_{l o}<1600$ (microchannels). As displayed in Table 6, the method only predicts $32.6 \%$ of the experimental data with a $\pm 30 \%$ error span. They reported overestimation of the heat transfer coefficient at low vapor qualities due to increased heat transfer rate associated to the onset of nucleate boiling in the experimental database they used. At high vapor qualities, this method tends to underestimate the heat transfer coefficient, presenting it as nearly independent of the vapor quality. This is one of the reasons why the $M A E$ and $M R E$ are so high. The method qualitatively predicts the heat transfer coefficient trend with the mass flux, although it displays tendencies for the saturation temperature that are opposite to what was observed experimentally. Lastly, the method displays a positive influence of the heat flux, especially at high mass fluxes, not found in the present data.

The heat transfer method for minichannels by Kanizawa et al. [37], based on the methodology proposed by Saitoh [41], predicts only $17 \%$ of the experimental database with less than a $\pm 30 \%$ error. Indeed, this method consistently overestimates the heat transfer coefficient values, especially at high mass and heat flux. It accounts for a positive influence of the mass flux on the heat transfer coefficient, but also a great dependence on the heat flux and on the saturation temperature, which are tendencies not observed for the present experimental database. It should be highlighted that the roughness of the tubes evaluated by them varies from 100 to $400 \mathrm{~nm}$, while polyimide films present roughness values of only between 12 and $35 \mathrm{~nm}$ [2].

Each of the methods was validated by verifying that they predict the trends observed in the experimental results, as described above. Figure 18 provides a comparison of all the methods with several experimental cases, involving their dependence on the mean vapor quality. It is observed the method by Cioncolini and Thome [38] predicts the slope of the heat transfer coefficient with the mean vapor quality and matches the experimental data almost within the uncertainty of these, except for the case in Figure 18 (a). In this case, all models fail to predict the heat transfer coefficient drop due to the onset of partial dryout conditions. The method by Kandlikar and Balasubramanian [40] exhibits low dependence on the vapor quality and underestimates the heat transfer coefficient at 35 and $41^{\circ} \mathrm{C}$. The method by Liu and Winterton [39] overestimates the heat transfer coefficient, like the correlation by Kanizawa et al. [37], this latter one providing the worse fit of the experimental data. 


\section{Conclusion}

This work showcases a new set of experimental results for average heat transfer coefficients of two-phase flow boiling R245fa in a $285 \mathrm{~mm}$-long, $2.689 \mathrm{~mm}$ ID, waterheated, very thin-walled and low-conductivity polyimide channel. Several conclusions are reached:

- A complete experimental database provides a wholly new database for the mean flow boiling heat transfer coefficient in a polyimide channel with R245fa, with mass fluxes ranging from 100 to $500 \mathrm{~kg} \mathrm{~m}^{-2} \mathrm{~s}^{-1}$, heat fluxes from 15 to $55 \mathrm{~kW} \mathrm{~m}^{-}$ ${ }^{2}$, vapor qualities between 0.05 and 0.80 , and saturation temperatures of 35,41 and $47^{\circ} \mathrm{C}$.

- In general, mean heat transfer coefficients increase with increasing mass flux and vapor quality. No significant dependence on the heat flux was observed. On the other hand, two trends are present regarding saturation temperature dependence: at low mass and heat fluxes, the mean heat transfer coefficient increases slightly for higher temperatures, while for higher mass and heat fluxes, the influence of the saturation temperature is stronger and shows the opposite trend.

- Results were compared to experimental data taken in the same experimental facility in smaller metallic channels. The heat transfer coefficient trends were qualitatively reproduced, although no local effects were observed, as the present work involves mean and not local heat transfer coefficients.

- Experimental results were compared with several leading heat transfer methods from the literature. The method by Cioncolini and Thome for convective boiling [38] provides the best results, with more than $80 \%$ of the experimental database predicted within a $\pm 30 \%$ error band, and reproducing the effects of flow boiling parameters on the heat transfer coefficients observed in the experimental results. This method is thus recommended for predicting flow boiling heat transfer coefficients in polyimide channels of less than $3 \mathrm{~mm}$ ID. The second best method is the one by Liu and Winterton [39], which however predicts a positive influence of the heat flux on the heat transfer coefficient, an effect not seen in 
the experimental results. The methods by Kandlikar and Balasubramanian [40], and by Kanizawa et al. [37] provided poor predictions, in general.

\section{Acknowledgements}

The authors gratefully acknowledge the support of the Swiss National Science Foundation (SNSF) for this work through the Doc.Mobility fellowship program, grant number P1ELP2-155264. The technical support provided by Mr. José Roberto Bogni and Mr. Hélio José Donizete Trebi is also acknowledged.

\section{References}

[1] Gómez Marzoa, M. et al. (2013). Thermal Studies of an Ultra-Low-Mass Cooling System for ALICE ITS Upgrade Project at CERN. In Proceedings of the 8th World Conference on Experimental Heat Transfer, Fluid Mechanics and Thermodynamics, Instituto Superior Técnico, Lisbon.

[2] Fiorenza, G. et al. (2013). An innovative polyimide microchannels cooling system for the pixel sensor of the upgraded ALICE inner tracker. In proceedings of the 5th IEEE International Workshop on Advances in Sensors and Interfaces (IWASI).

[3] Tibiriçá, C. B. and Ribatski, G. (2010). Flow boiling heat transfer of R134a and R245fa in a $2.3 \mathrm{~mm}$ tube. International Journal of Heat and Mass Transfer, 53(11), 2459-2468. DOI: 10.1016/j.ijheatmasstransfer.2010.01.038

[4] Pike-Wilson, E.A and Karayiannis, T. G. Flow boiling of R245fa in $1.1 \mathrm{~mm}$ diameter stainless steel, brass and copper tubes. Experimental Thermal and Fluid Science, 59:166-183, 2014.

[5] Dupont, V., Thome, J. R., and Jacobi, A. M. (2004). Heat transfer model for evaporation in microchannels. Part II: comparison with the database. International Journal of Heat and Mass Transfer, 47(14), 3387-3401. 
[6] Karayiannis, T.G., Mahmoud, M. M., Kenning, D.B.R. (2012). A study of discrepancies in flow boiling results in small to microdiameter metallic tubes, Exp. Thermal Fluid Science, v. 36, p 126-142.

[7] Mikro-Polyimid Kapillarschlauch Dataheet. Detakta, 2013.

[8] Bertsch S. S., Groll, E. A., and Garimella, S. V. (2008). Review and Comparative Analysis of Studies on Saturated Flow Boiling in Small Channels. Nanoscale and Microscale Thermophysical Engineering. Vol. 12 (3), pp. 187227

[9] Cheng, G. Ribatski and J. R. Thome (2007). Two-phase flow patterns and flow pattern maps: fundamentals and applications. Applied Mechanics Reviews, v. 61, p. 050802-1.

[10] Kandlikar, S. G. and Grande, W. J. (2003). Evolution of Microchannel Flow Passages - Thermohydraulic Performance and Fabrication Technology. Heat transfer engineering, 24(1), 3-17. DOI:10.1080/01457630304040

[11] The ALICE Collaboration (2013). Technical Design Report for the Upgrade of the ALICE Inner Tracking System. Technical Report CERN-LHCC2013-024. ALICE-TDR-017, CERN, Geneva.

[12] Mehendale, S. S., Jacobi, A. M., and Shah, R. K. (2000). Fluid flow and heat transfer at micro-and meso-scales with application to heat exchanger design. Applied Mechanics Reviews, 53(7), 175-193. doi:10.1115/1.3097347

[13] Churchill, S. W and Chu H. H. S. (1975). Correlating Equations for Laminar and Turbulent Free Convection from a Horizontal Cylinder. Int. J. Heat Mass Transfer, vol. 18, p. 1049

[14] Matkovic, M. et al (2009). Experimental study on condensation heat transfer inside a single circular minichannel, Int. Journal of Heat and Mass Transfer, Vol. 52, Iss. 9-10, pp. 2311-2323, ISSN 0017-9310.

[15] Incropera, F. (2007) Fundamentals of Heat and Mass Transfer. John Wiley \& Sons. ISBN:0470088400 
[16] Gnielinski, V. (1976). New equations for heat and mass transfer in turbulent pipe and channel flow. Int Chem Eng 16:359-368

[17] VDI Heat Atlas. Verein Deutscher Ingenieure, VDI-Gesellschaft Vehrfahrenstechnik und Chemieingenieurwesen (GVC). 2nd Edition. SpringerVerlag Berlin Heidelberg.

[18] Kays, W. m and London, A. L. (1984). Compact heat exchangers, $3^{\text {rd }}$ Edition. McGraw-Hill, New York, 1984.

[19] Petukhov, B. S. (1970). Heat transfer and friction in turbulent pipe flow with variable physical properties. Advances in heat transfer, 6(503), i565.

[20] Dittus, F. W. and Boelter, L. M. K. (1930). Heat transfer in automobile radiators of the tubular type. Publications in Engineering. University of California, v.2, pp. 443-461.

[21] Gnielinski, V. (2009) Heat transfer coefficients for turbulent flow in concentric annular ducts. Heat Transfer Engineering 30(6):431-436

[22] Churchill, S.W. (1977). Friction factor equation spans all fluid-flow regimes, Chem. Eng., 91

[23] Müller-Steinhagen, H. and Heck, K. (1986). A simple friction pressure drop correlation for two-phase flow in pipes, Chem. Eng. Process, vol. 20, pp. 297-308.

[24] Friedel, L. (1980). Pressure drop during gas/vapour-liquid flow in pipes, Int. Chem. Engineering 20, 352-367

[25] Da Silva, J. and Ribatski G. (2013). Two-phase frictional pressure drop of halocarbon refrigerants inside small diameter tubes: data analyses and the proposition of a new frictional pressure drop correlation. 8th International Conference on Multiphase Flow ICMF 2013, Jeju, Korea, May 26 - 31, 2013

[26] Sempértegui-Tapia, D. F. (2016). Experimental analysis of the crosssectional geometry effect and low GWP refrigerants performance during convective boiling inside micro-channels. PhD Thesis. Escola de Engenharia de São Carlos, Universidade de São Paulo, São Carlos. 
[27] Collier, J. G. and Thome, J. R (1996). Convective Boiling and Condensation. Oxford University Press.

[28] Steiner, D. (2010). H3.1 Flow Patterns in Evaporator Tubes. VDI Heat ATLAS, Second Edition. Düsseldorf, VDI-Gessellschaft Verfahrenstechnik und Chemieingenieurwesen (GCV).

[29] Rouhani, S. Z. and Axelsson, E. (1970). Calculation of void volume fraction in the subcooled and quality boiling regions. Int. J. Heat and Mass Trans. vol. 13(2), pp 383-393.

[30] Abernethy, R. B. and Thompson, J. W. (1973). Handbook Uncertainty in Gas Turbine Measurements, Arnold Engineering Development Center, Arnold Air Force Station, Tennessee.

[31] Taylor, B.N. and Kuyatt, C.E. (1994). Guidelines for Evaluating and Expressing the Uncertainty of NIST Measurement Results. NIST Technical Note 25.

[32] Kline, S. J. and McClintock, F. A. (1953). Describing uncertainties in single-sample experiments. Mechanical Engineering, 75:3-8.

[33] Sempértegui-Tapia, D., De Oliveira Alves, J., and Ribatski, G. Twophase flow characteristics during convective boiling of halocarbon refrigerants inside horizontal small-diameter tubes. Heat Transfer Engineering 34.13 (2013): 1073-1087.

[34] Kew, P. A., and Cornwell, K. (1997). Correlations for the prediction of boiling heat transfer in small-diameter channels. Applied Thermal Engineering, 17(8), 705-715. DOI: 10.1016/S1359-4311(96)00071-3

[35] Ong, C. L., and Thome, J. R. (2011). Macro-to-microchannel transition in two-phase flow: Part 2-Flow boiling heat transfer and critical heat flux. Experimental thermal and fluid science, 35(6), 873-886. DOI: 10.1016/j.expthermflusci.2010.12.003

[36] Wojtan, L., Revellin, R., and Thome, J. R. (2006). Investigation of saturated critical heat flux in a single, uniformly heated microchannel. 
Experimental Thermal and Fluid Science, 30(8), 765-774. doi:10.1016/j.expthermflusci.2006.03.006

[37] Kanizawa, F. T., Tibiriçá, C. B. and Ribatski, G. (2016). Heat transfer during convective boiling inside microchannels. Int. J. Heat Mass Transfer, 93, pp 566-583.

[38] Cioncolini, A. and Thome, J. R. (2011). Algebraic turbulence modeling in adiabatic and evaporating annular two-phase flow. International Journal of Heat and Fluid Flow, 32(4), 805-817. DOI: 10.1016/j.ijheatfluidflow.2011.05.006

[39] Liu, Z. and Winterton, R. H. S. (1991). A General Correlation for Saturated and Subcooled Flow Boiling in Tubes and Annuli Based on a Nucleate Pool Boiling Equation, Int. J. Heat Mass Transfer, 34, pp. 2759-2766

[40] Kandlikar, S. G., and Balasubramanian, P. (2004). An extension of the flow boiling correlation to transition, laminar, and deep laminar flows in minichannels and microchannels. Heat Transfer Engineering, 25(3), 86-93. DOI:10.1080/01457630490280425

[41] Saitoh, S., Daiguji, H., and Hihara, E. (2007). Correlation for boiling heat transfer of R-134a in horizontal tubes including effect of tube diameter. International Journal of Heat and Mass Transfer, 50(25), 5215-5225. DOI: 10.1016/j.ijheatmasstransfer.2007.06.019 


\section{Tables}

Table 1 - Thermophysical properties of the R245fa refrigerant at three saturation temperatures

Table 2 - Summary of the conditions in the water-water tests and the results of the experimental thermal resistance of conduction across the tube wall.

Table 3 - Mean absolute error $(M A E)$ of the heat transfer coefficient between the water and the polyimide tube outer wall in the annulus given by several heat transfer correlations versus the experimental values.

Table 4 - Statistical analysis of the comparison between experimental and calculated two-phase pressure drops for the different methods used for evaluating the frictional component.

Table 5 - Experimental uncertainty of the measured parameters.

Table 6 - Statistical analysis of the comparison between experimental and predicted mean two-phase flow boiling heat transfer coefficients in the polyimide channel.

Table 1 - Thermophysical properties of the R245fa refrigerant at three saturation temperatures

\begin{tabular}{ccccccc}
\hline$T_{\text {sat }}\left[{ }^{\circ} \mathrm{C}\right]$. & $p_{\text {sat }}[\mathrm{kPa}]$ & $\rho_{l}\left[\mathrm{~kg} \mathrm{~m}^{-3}\right]$ & $v_{l}\left[\mathrm{~m}^{3} \mathrm{~kg}^{-1}\right]$ & $v_{v}\left[\mathrm{~m}^{3} \mathrm{~kg}^{-1}\right]$ & $k_{l}\left[\mathrm{~W} \mathrm{~m}^{-1} \mathrm{~K}^{-1}\right]$ & $\mu_{l}[\mu \mathrm{Pa} \mathrm{s}]$ \\
\hline 35 & 212 & 1310.9 & 12.0 & 0.0832 & 0.085 & 359.2 \\
41 & 259 & 1293.8 & 14.6 & 0.0686 & 0.083 & 333.8 \\
47 & 314 & 1276.4 & 17.6 & 0.0570 & 0.081 & 310.6
\end{tabular}

Table 2 - Summary of the conditions in the water-water tests and the results of the experimental thermal resistance of conduction across the tube wall. The water flows inside the polyimide tube and in the annular space outside it are counter-current.

\begin{tabular}{ccccccc}
\hline Case nr. & $T_{\text {ann }}\left[{ }^{\circ} \mathrm{C}\right]$ & $T_{\text {int }}\left[{ }^{\circ} \mathrm{C}\right]$ & $R e_{\text {ann }}[-]$ & $R e_{\text {int }}[-]$ & $R_{\text {cond,wall }}\left[\mathrm{K} \mathrm{W}^{-1}\right]$ & $\mathrm{Uc}\left(R_{\text {cond,wall }}\right)\left[\mathrm{K} \mathrm{W}^{-1}\right]$ \\
\hline 1 & 50 & 20 & $4500-9760$ & $\sim 21500$ & 0.0902 & 0.0082 \\
2 & 60 & 30 & $5350-11400$ & $\sim 28000$ & 0.0901 & 0.0089 \\
3 & 40 & 10 & $2670-8070$ & $\sim 16700$ & 0.0968 & 0.0090 \\
\hline & & & Average & 0.0924 & 0.0087
\end{tabular}

Table 3 - Mean absolute error (MAE) of the heat transfer coefficient between the water and the polyimide tube outer wall in the annulus given by several heat transfer correlations versus the experimental values.

Mean absolute error [\%]

Case $\quad T_{a n n}\left[{ }^{\circ} \mathrm{C}\right] \quad T_{\text {int }}\left[{ }^{\circ} \mathrm{C}\right] \quad$ Gnielinski [16] Petukhov [19] $\quad$ Gnielinski-VDI [21] Dittus-Boelter [20]




\begin{tabular}{ccccccc}
\hline 0 & 50 & 20 & 22.6 & 6.4 & 11.7 & 31.6 \\
1 & 50 & 20 & 30.7 & 12.2 & 20.3 & 39.8 \\
2 & 60 & 30 & 48.3 & 29.2 & 33.5 & 58.2 \\
3 & 40 & 10 & 19.4 & 3.1 & 18.9 & 25.7 \\
4 & Water & R245fa & 14.8 & 16.6 & - & - \\
\hline
\end{tabular}

Table 4 - Statistical analysis of the comparison between experimental and calculated two-phase pressure drops for the different methods used for evaluating the frictional component.

\begin{tabular}{cccc}
\hline Author/method & $\lambda_{20 \%}[\%]$ & $M R E[\%]$ & $M A E[\%]$ \\
\hline Müller-Steinhagen and Heck [23] & 81.3 & 10.3 & 11.1 \\
Friedel [24] & 78.6 & 10.6 & 11.5 \\
Da Silva-Ribatski [25] & 75.9 & 12.4 & 12.7 \\
Sempértegui Tapia-Ribatski [26] & 83.0 & 9.5 & 10.0 \\
\hline
\end{tabular}

Table 5 - Experimental uncertainty of the measured parameters.

\begin{tabular}{lc}
\hline Polyimide channel ID & $2.689 \pm 0.025 \mathrm{~mm}$ \\
Polyimide channel OD & $2.816 \pm 0.053 \mathrm{~mm}$ \\
Polyimide channel heated length & $285 \pm 1 \mathrm{~mm}$ \\
Water enclosure ID & $4.925 \pm 0.050 \mathrm{~mm}$ \\
Pre-heater electric power & $\pm 0.8 \% \mathrm{~W}$ \\
Temperature (water) & $\pm 0.10 \mathrm{~K}$ \\
Temperature (R245fa) & $\pm 0.11 \mathrm{~K}$ \\
Temperature (tube walls) & $\pm 0.11 \mathrm{~K}$ \\
Water flow rate & $\pm 0.031 \mathrm{~L} \mathrm{~min}^{-1}$ \\
Coriolis flow meter (R245fa) & $\pm 0.1 \% \mathrm{~g} \mathrm{~s}^{-1}$ \\
Absolute pressure & $\pm 4.50 \mathrm{kPa}$ \\
Differential pressure & $\pm 0.15 \mathrm{kPa}$ \\
\hline
\end{tabular}

Table 6 - Statistical analysis of the comparison between experimental and predicted mean two-phase flow boiling heat transfer coefficients in the polyimide channel.

\begin{tabular}{lllccc}
\hline & & \multicolumn{4}{c}{ Method } \\
\cline { 3 - 6 } Database & Parameter & $\begin{array}{c}\text { Liu-Winterton } \\
{[39]}\end{array}$ & $\begin{array}{c}\text { Kandlikar- } \\
\text { Balasubramanian [40] }\end{array}$ & $\begin{array}{c}\text { Cioncolini- } \\
\text { Thome [38] }\end{array}$ & $\begin{array}{c}\text { Kanizawa } \text { et } \\
\text { al. [37] }\end{array}$ \\
\hline \multirow{3}{*}{ Entire database } & $\lambda_{30 \%}[\%]$ & 50.7 & 26.9 & 73.5 & 22.4 \\
& MAE [\%] & 50.7 & 43.2 & 21.2 & 60.5 \\
& MRE [\%] & 35.7 & -37.9 & 18.0 & 59.5 \\
\hline \multirow{3}{*}{$\mathrm{Uc}\left(h_{t, m}\right)<35 \%$} & $\lambda_{30 \%}[\%]$ & 44.2 & 32.6 & 81.4 & 16.9 \\
& MAE [\%] & 44.2 & 39.2 & 18.0 & 65.8 \\
& MRE [\%] & 28.9 & -32.8 & 15.0 & 65.6 \\
\hline
\end{tabular}




\section{Figures}

Figure 1 - Schematic view of the test rig (not scaled) Dimensions expressed in $\mathrm{mm}$. Flow is from right to left.

Figure 2 - CFD simulation of the heating water flow thermal stratification: (a) water temperature $\left[{ }^{\circ} \mathrm{C}\right]$ at 3 sections of the annulus and simulation boundary conditions; (b) temperature along three longitudinal axis: top, bottom, and central part of the annulus, as indicated in (a).

Figure 3 - Heating water loop scheme.

Figure 4 - Water-water test thermal resistances vs. annulus Reynolds number. The annulus water flow displays an inlet temperature of $50^{\circ} \mathrm{C}$ and water flow inside the polyimide channel, $20^{\circ} \mathrm{C}$.

Figure 5 - Comparison between the experimental R245fa single-phase pressure drop and the values obtained with correlations, versus the Reynolds number inside the polyimide tube

Figure 6 - Single-phase energy balances at the: (a) pre-heater, keeping the polyimide tube in adiabatic conditions; (b) test section (polyimide tube), with no power applied to the pre-heater.

Figure 7 - Single-phase heat transfer coefficient in the polyimide channel: comparison between predictions and experimental values calculated from the heat loads measured in the water $\left(\dot{Q}_{n e t}\right)$ and the R245fa flows $\left(\dot{Q}_{R 245 f a}\right)$.

Figure 8 - Experimental, theoretical (frictional, calculated with MüllerSteinhagen and Heck correlation [23], plus the momentum pressure gradient), and singular two-phase, adiabatic pressure drops in the test rig versus the mean vapor quality.

Figure 9 - Theoretical (frictional pressure drop correlation by Müller-Steinhagen and Heck correlation [23], plus the singular pressure drop, plus the momentum pressure gradient) versus the experimental pressure drop in several two-phase flow diabatic cases.

Figure 10 - Repeatability of the diabatic two-phase flow boiling experimental tests.

Figure 11 - Two-phase flow stratification recorded at the $2.1 \mathrm{~mm}$ ID visualization section, at $G=200 \mathrm{~kg} \mathrm{~m}^{-2} \mathrm{~s}^{-1}, x=0.05, T_{\text {sat }}=35^{\circ} \mathrm{C}$. Flow is from right to left. 
Figure 12 - Influence of the mass flux on the heat transfer coefficient. Highspeed flow images of the four points with the highest vapor qualities (1-4) for the lowest mass velocity are displayed illustrating the captured partial dryout conditions.

Figure 13 - Influence of the mass flux on the heat transfer coefficient for two different saturation temperatures: (a) $35^{\circ} \mathrm{C}$, and (b) $41^{\circ} \mathrm{C}$.

Figure 14 - Effect of the heat flux on the mean heat transfer coefficient, plotted against: (a) mean vapor qualities in the polyimide channel; (b) inlet and outlet vapor qualities in the polyimide channel.

Figure 15 - Effect of the heat flux on the mean heat transfer coefficient plotted against the mean vapor quality at $T_{s a t}=41^{\circ} \mathrm{C}$ and $G=400 \mathrm{~kg} \mathrm{~m}^{-2} \mathrm{~s}^{-1}$.

Figure 16 - Effect of the saturation temperature on the mean heat transfer coefficient, plotted against the mean vapor quality in the test section, at: (a) $G=200 \mathrm{~kg}$ $\mathrm{m}^{-2} \mathrm{~s}^{-1}$ and $q_{t s}=15 \mathrm{~kW} \mathrm{~m}^{-2}$, and (b) $G=400 \mathrm{~kg} \mathrm{~m}^{-2} \mathrm{~s}^{-1}$ and $q_{t s}=45 \mathrm{~kW} \mathrm{~m}^{-2}$.

Figure 17 - Comparison of the experimental data taken in the present work with similar studies with R245fa: (a) data by Tibiriçá and Ribatski [3], and Kanizawa et al. [37] in a $2.3 \mathrm{~mm}$ ID stainless steel pipe; (b) influence of the heat flux as recorded by Kanizawa et al. [37].

Figure 18 - Comparison of the experimental data with four heat transfer coefficient prediction methods in the literature at different conditions: (a) $G=100 \mathrm{~kg} \mathrm{~m}^{-2}$ $\mathrm{s}^{-1}, q_{t s}=15 \mathrm{~kW} \mathrm{~m}{ }^{-2}, T_{s a t}=41^{\circ} \mathrm{C}$; (b) $G=200 \mathrm{~kg} \mathrm{~m}^{-2} \mathrm{~s}^{-1}, q_{t s}=25 \mathrm{~kW} \mathrm{~m}^{-2}, T_{\text {sal }}=35^{\circ} \mathrm{C}$; (c) $G=300 \mathrm{~kg} \mathrm{~m}^{-2} \mathrm{~s}^{-1}, q_{t s}=25 \mathrm{~kW} \mathrm{~m}^{-2}, T_{s a l}=41^{\circ} \mathrm{C}$; (d) $G=400 \mathrm{~kg} \mathrm{~m}^{-2} \mathrm{~s}^{-1}, q_{t s}=45 \mathrm{~kW} \mathrm{~m}^{-2}$, $T_{\text {sat }}=47^{\circ} \mathrm{C}$

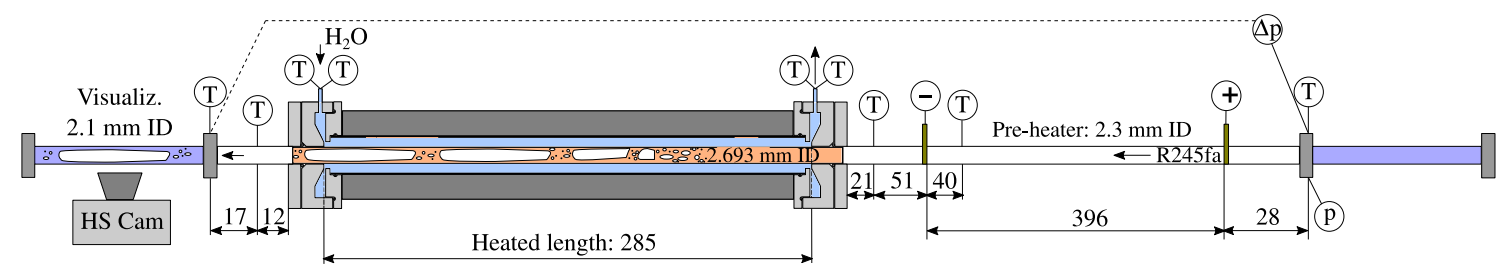

Figure 1 - Schematic view of the test rig (not scaled) Dimensions expressed in $\mathbf{m m}$. Flow is from right to left. 


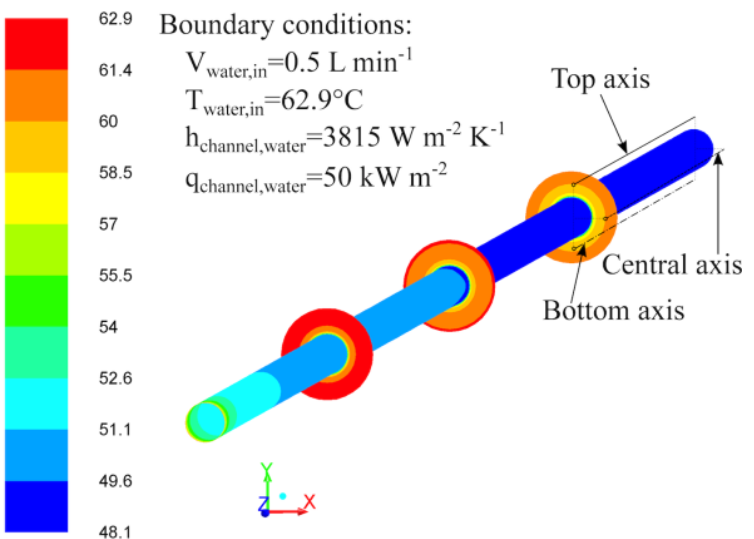

( a )

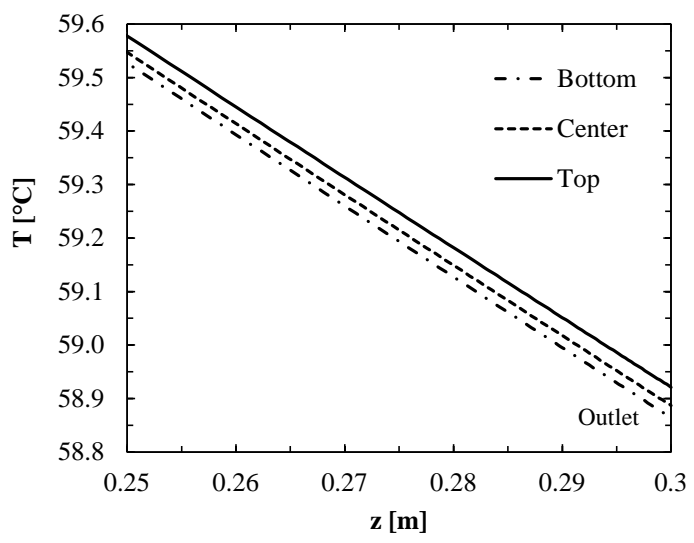

( b )

Figure 2 - CFD simulation of the heating water flow thermal stratification: (a) water temperature $\left[{ }^{\circ} \mathrm{C}\right]$ at 3 sections of the annulus and simulation boundary conditions; (b) temperature along three longitudinal axis: top, bottom, and central part of the annulus, as indicated in (a).

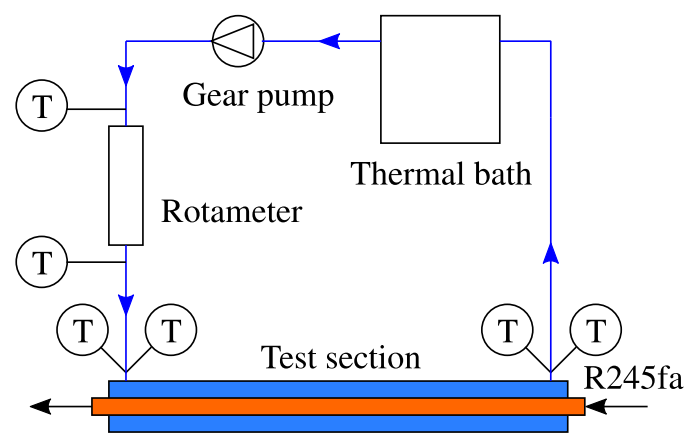

Figure 3 - Heating water loop scheme.

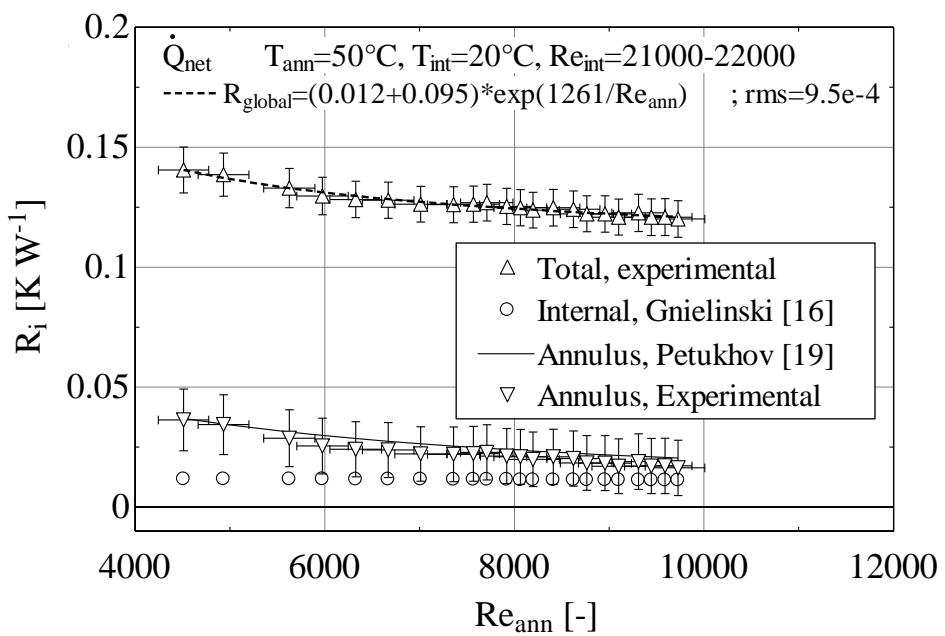

Figure 4 - Water-water test thermal resistances vs. annulus Reynolds number. The annulus water flow displays an inlet temperature of $50^{\circ} \mathrm{C}$ and water flow inside the polyimide channel, $20^{\circ} \mathrm{C}$. 


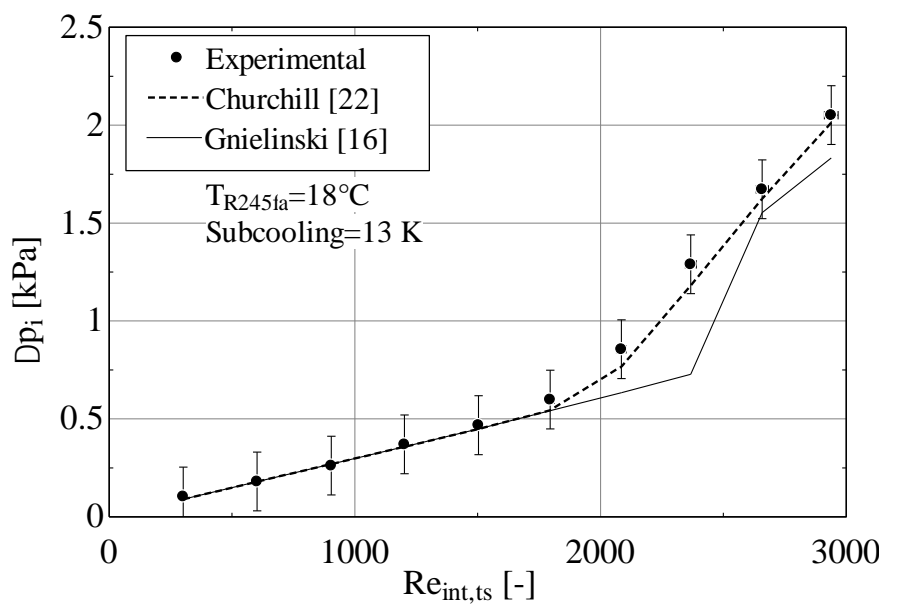

Figure 5 - Comparison between the experimental R245fa single-phase pressure drop and the values obtained with correlations, versus the Reynolds number inside the polyimide tube
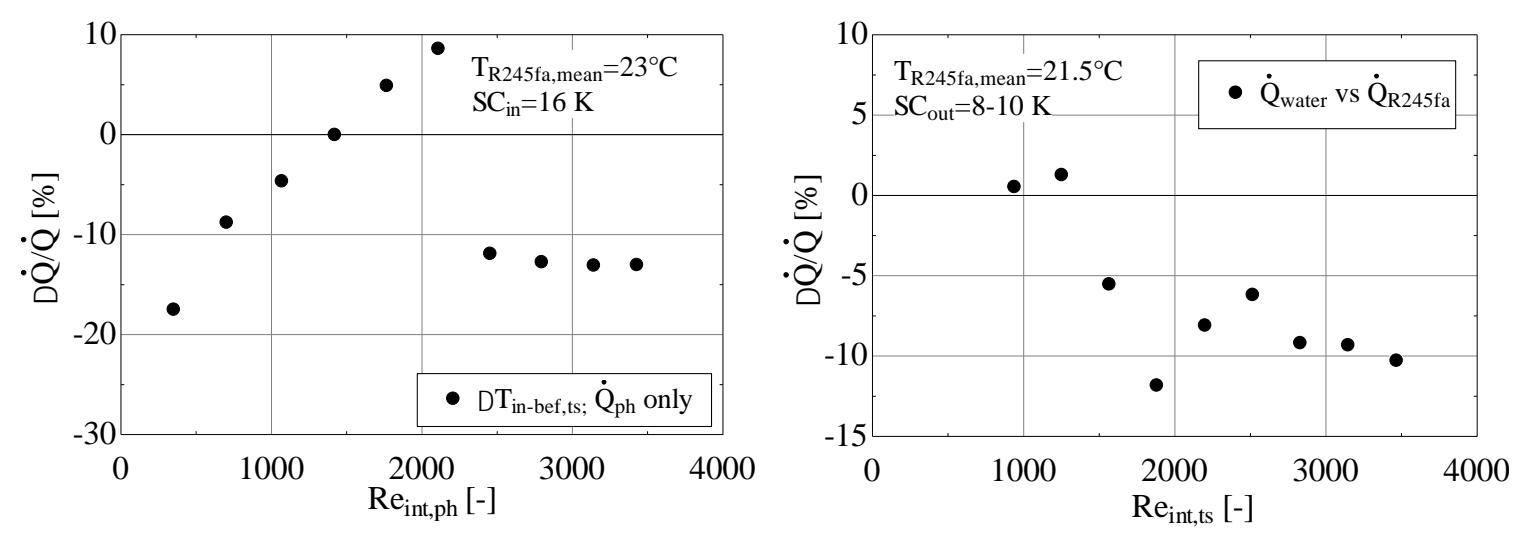

Figure 6 - Single-phase energy balances at the: (a) pre-heater, keeping the polyimide tube in adiabatic conditions; (b) test section (polyimide tube), with no power applied to the pre-heater.

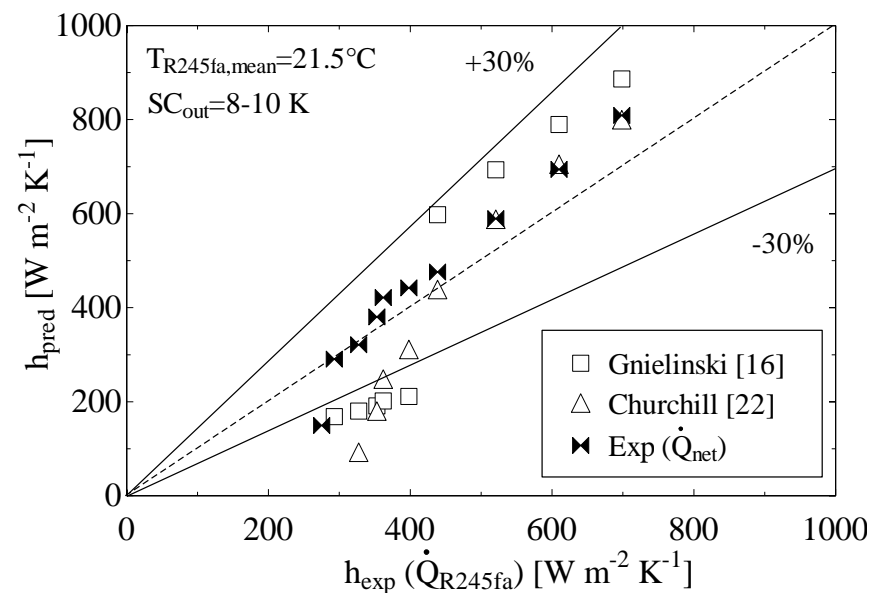

Figure 7 - Single-phase heat transfer coefficient in the polyimide channel: comparison between predictions and experimental values calculated from the heat loads measured in the water $\left(\dot{Q}_{n e t}\right)$ and the R245fa flows $\left(\dot{Q}_{R 245 f a}\right)$. 


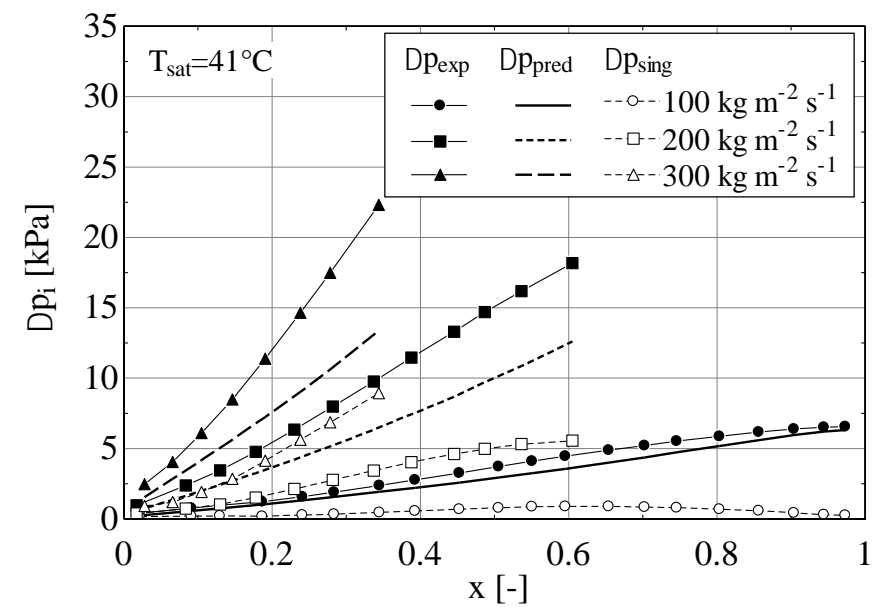

Figure 8 - Experimental, theoretical (frictional, calculated with Müller-Steinhagen and Heck correlation [23], plus the momentum pressure gradient), and singular two-phase, adiabatic pressure drops in the test rig versus the mean vapor quality.

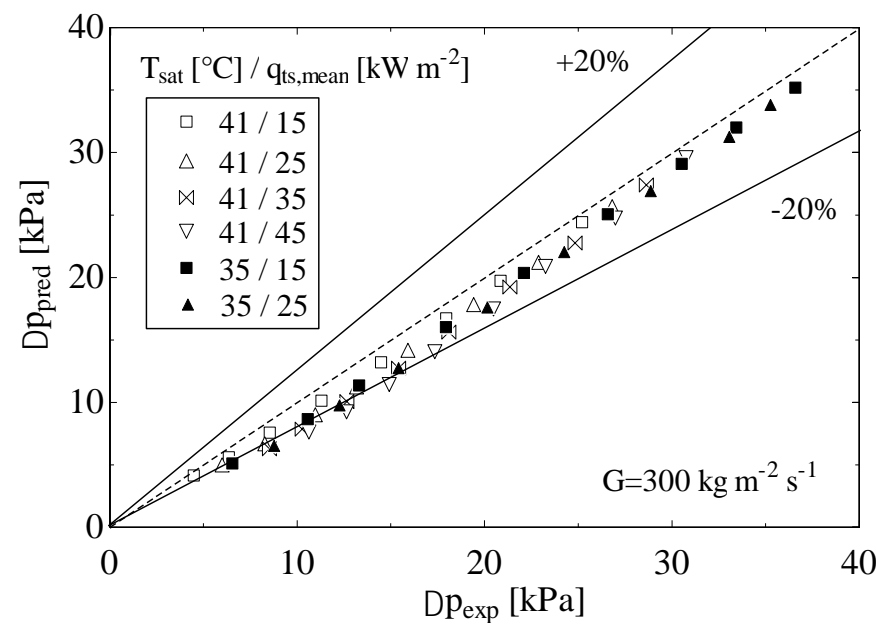

Figure 9 - Theoretical (frictional pressure drop correlation by Müller-Steinhagen and Heck correlation [23], plus the singular pressure drop, plus the momentum pressure gradient) versus the experimental pressure drop in several two-phase flow diabatic cases.

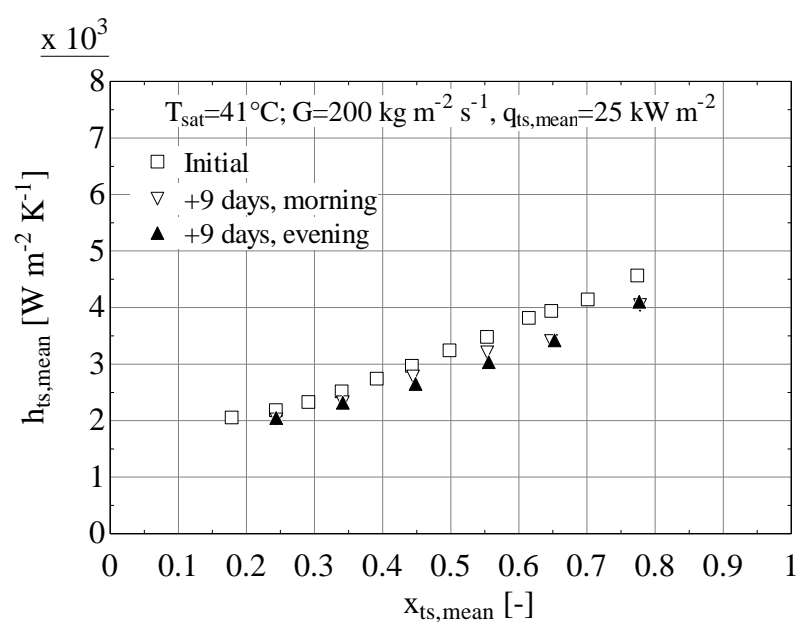

Figure 10 - Repeatability of the diabatic two-phase flow boiling experimental tests. 


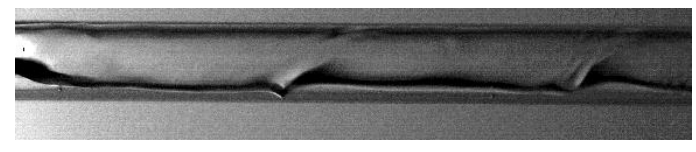

Figure 11 - Two-phase flow stratification recorded at the $2.1 \mathrm{~mm}$ ID visualization section, at $G=200 \mathrm{~kg} \mathrm{~m}^{-2} \mathrm{~s}^{-1}$, $x=0.05, T_{s a t}=35^{\circ} \mathrm{C}$. Flow is from right to left.

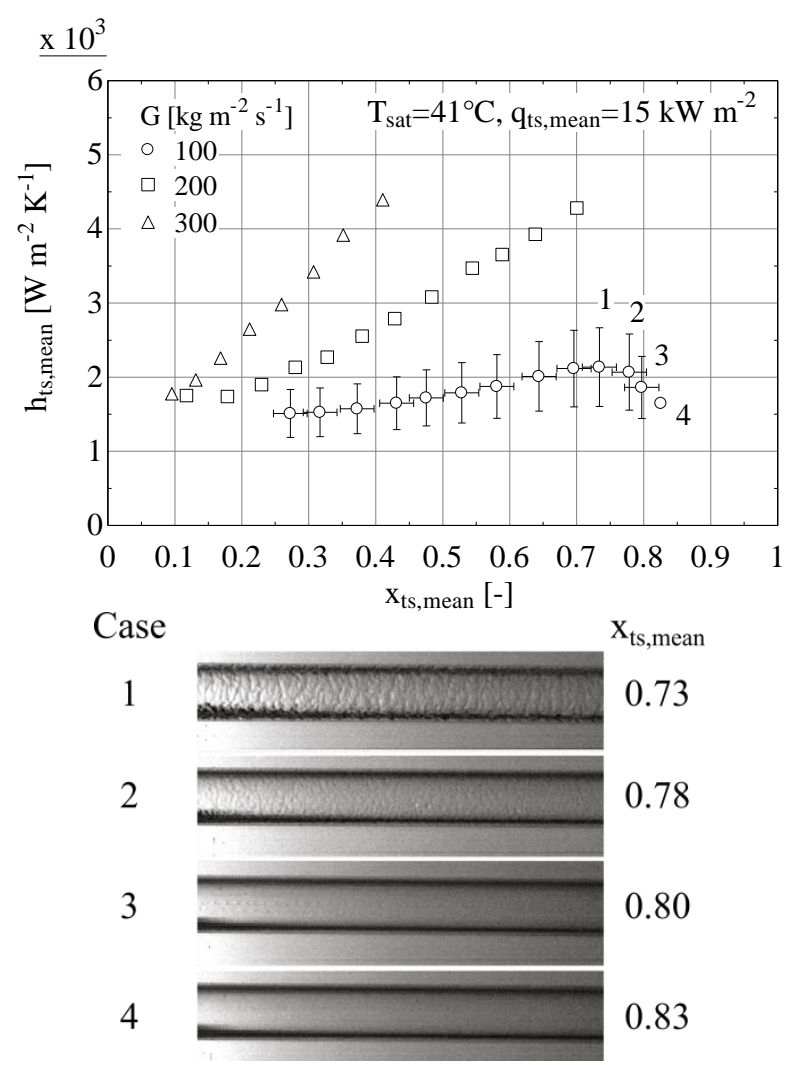

Figure 12 - Influence of the mass flux on the heat transfer coefficient. High-speed flow images of the four points with the highest vapor qualities (1-4) for the lowest mass velocity are displayed illustrating the captured partial dryout conditions. 


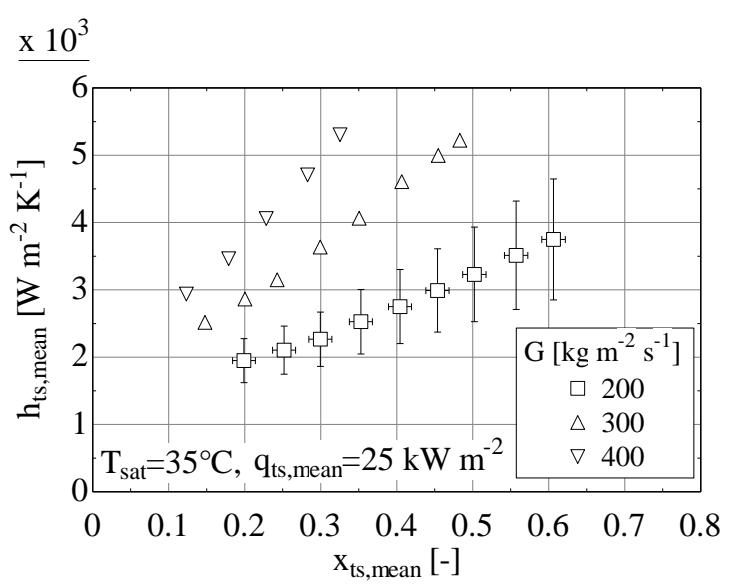

(a)

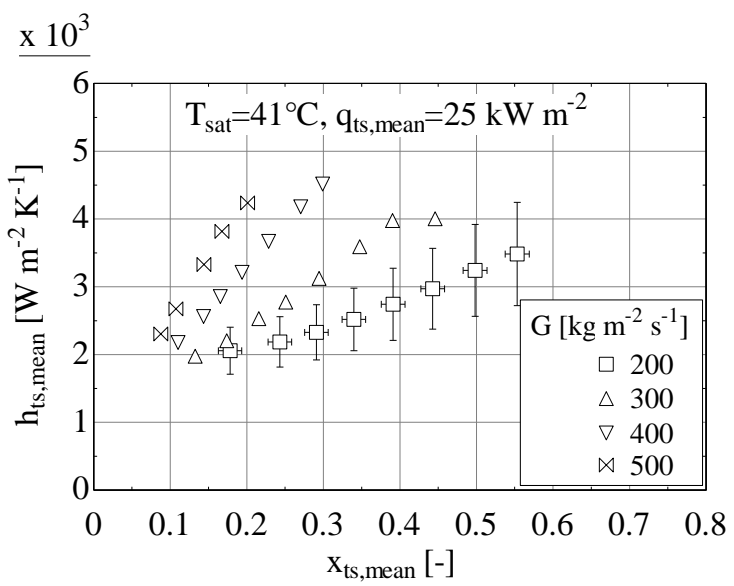

(b)

Figure 13 - Influence of the mass flux on the heat transfer coefficient for two different saturation temperatures: (a) $35^{\circ} \mathrm{C}$, and (b) $41^{\circ} \mathrm{C}$.

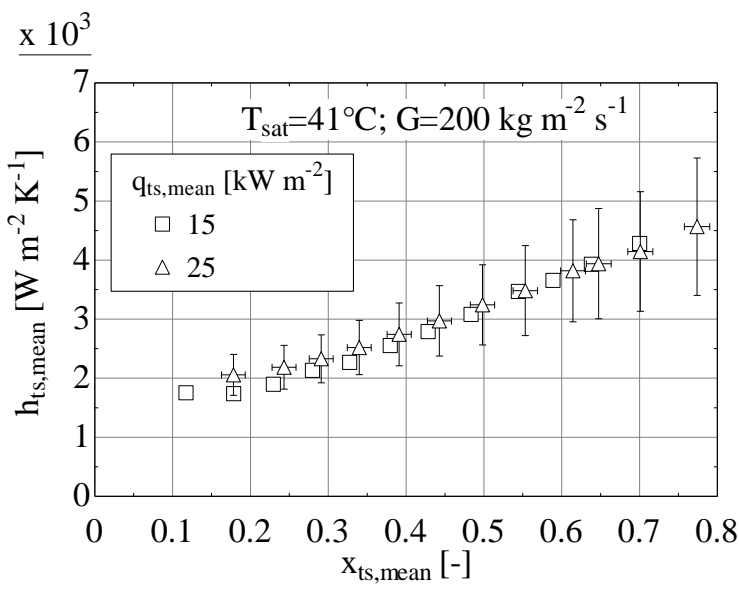

(a)

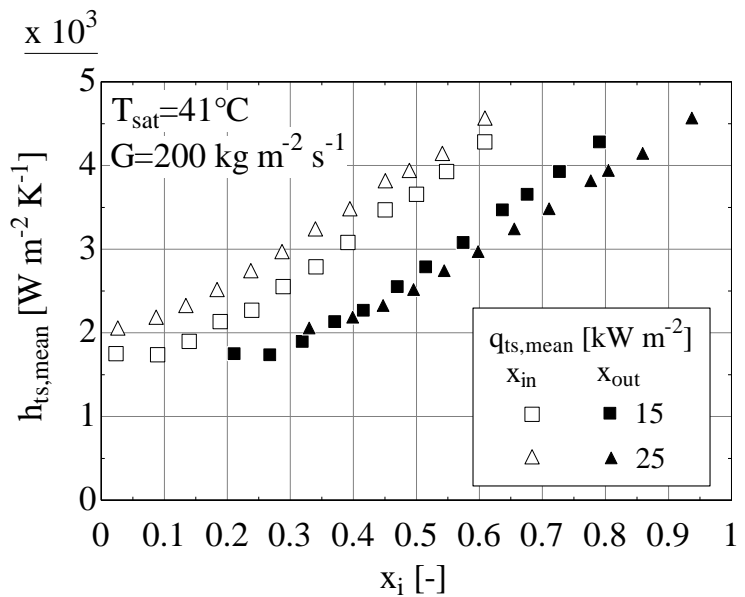

(b)

Figure 14 - Effect of the heat flux on the mean heat transfer coefficient, plotted against: (a) mean vapor qualities in the polyimide channel; (b) inlet and outlet vapor qualities in the polyimide channel.

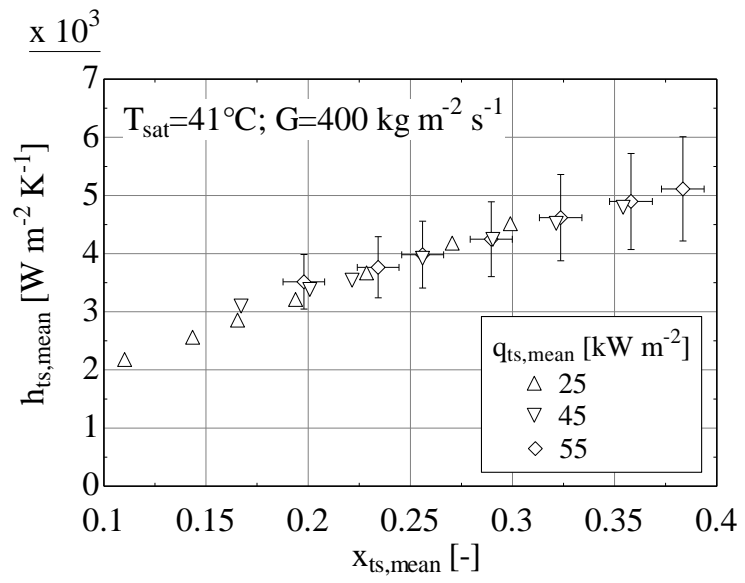

(a)

(b)

Figure 15 - Effect of the heat flux on the mean heat transfer coefficient plotted against the mean vapor quality at $T_{\text {sat }}=41^{\circ} \mathrm{C}$ and $G=400 \mathrm{~kg} \mathrm{~m}^{-2} \mathrm{~s}^{-1}$. 


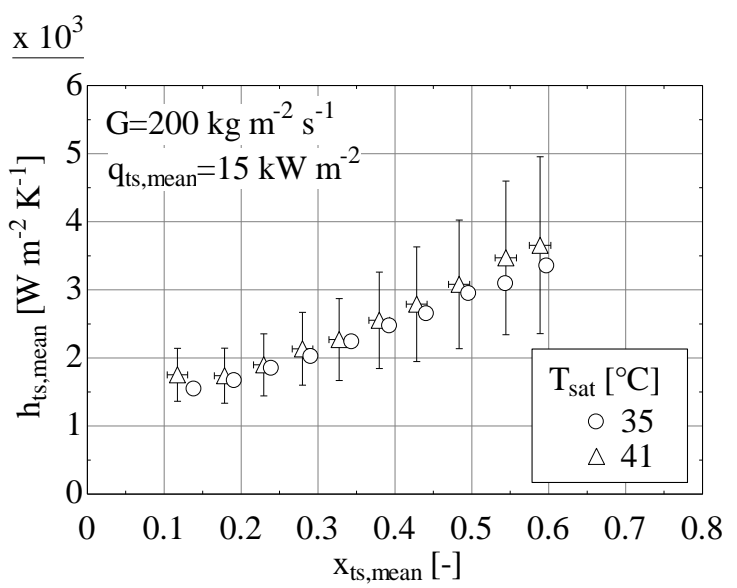

(a)

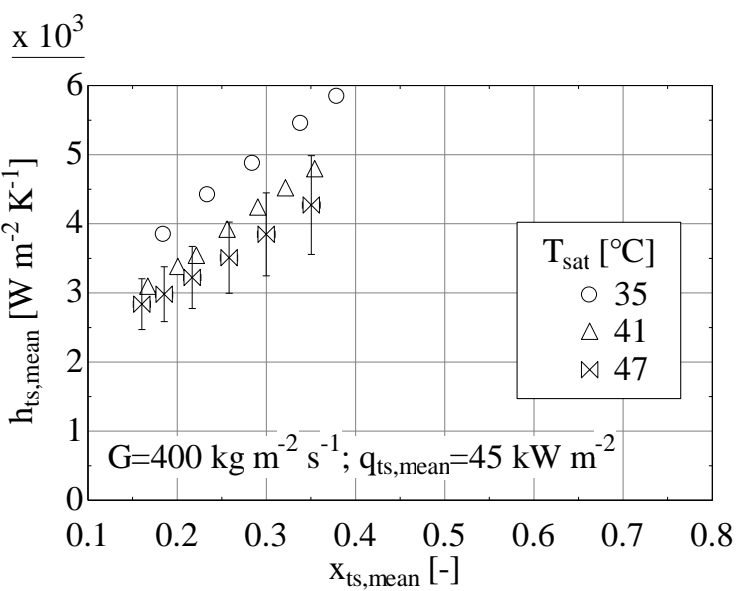

(b)

Figure 16 - Effect of the saturation temperature on the mean heat transfer coefficient, plotted against the mean vapor quality in the test section, at: (a) $G=200 \mathrm{~kg} \mathrm{~m}^{-2} \mathrm{~s}^{-1}$ and $q_{t s}=15 \mathrm{~kW} \mathrm{~m}^{-2}$, and (b) $G=400 \mathrm{~kg} \mathrm{~m}^{-2} \mathrm{~s}^{-1}$ and $q_{t s}=45 \mathrm{~kW} \mathrm{~m}^{-2}$.

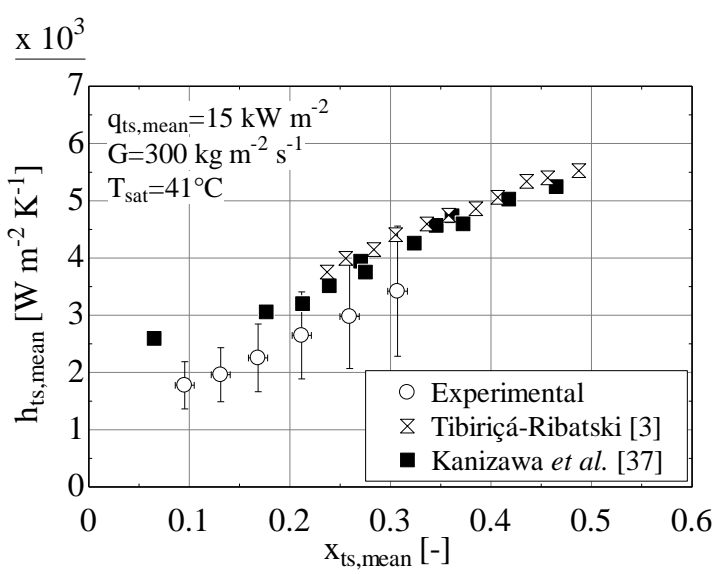

(a)

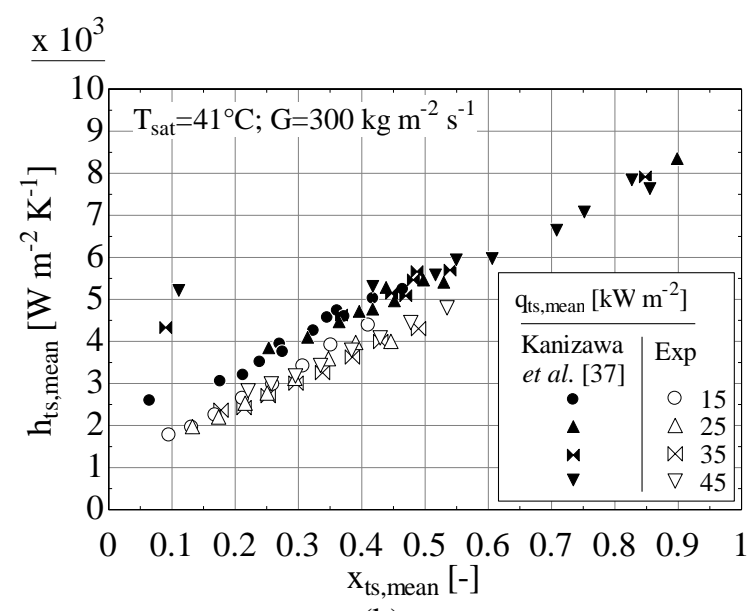

(b)

Figure 17 - Comparison of the experimental data taken in the present work with similar studies with R245fa: (a) data by Tibiriçá and Ribatski [3], and Kanizawa et al. [37] in a $2.3 \mathrm{~mm}$ ID stainless steel pipe; (b) influence of the heat flux as recorded by Kanizawa et al. [37]. 


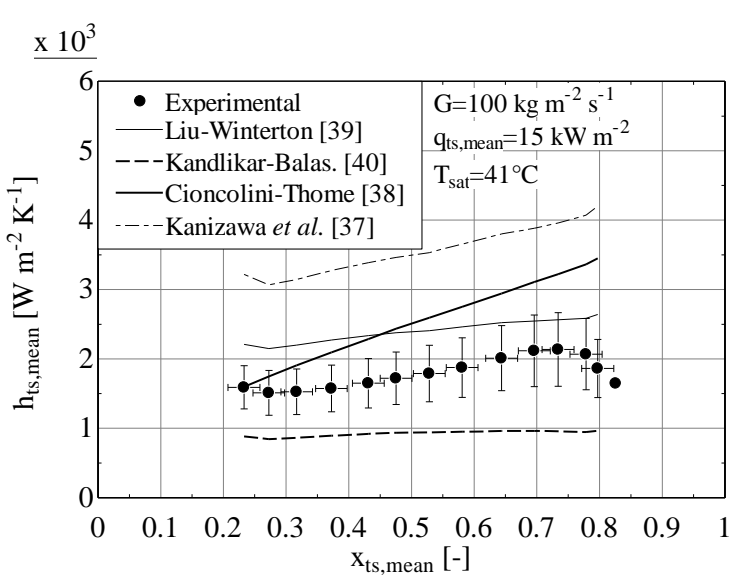

(a)

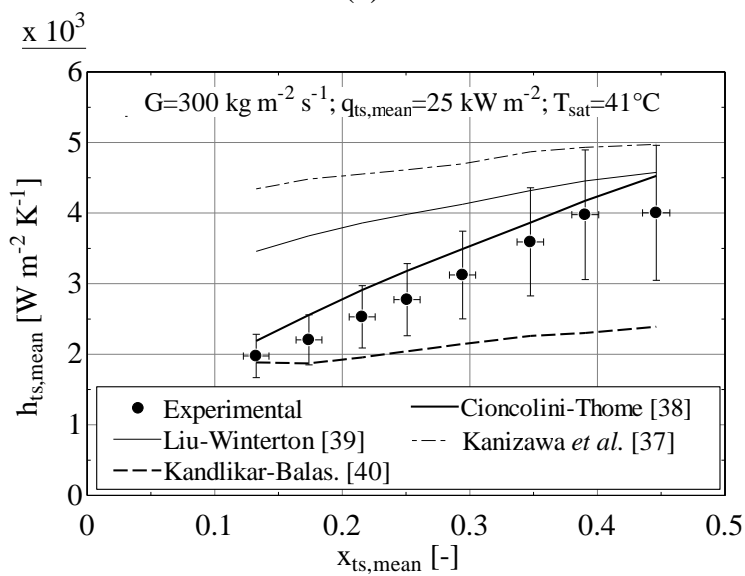

(c)

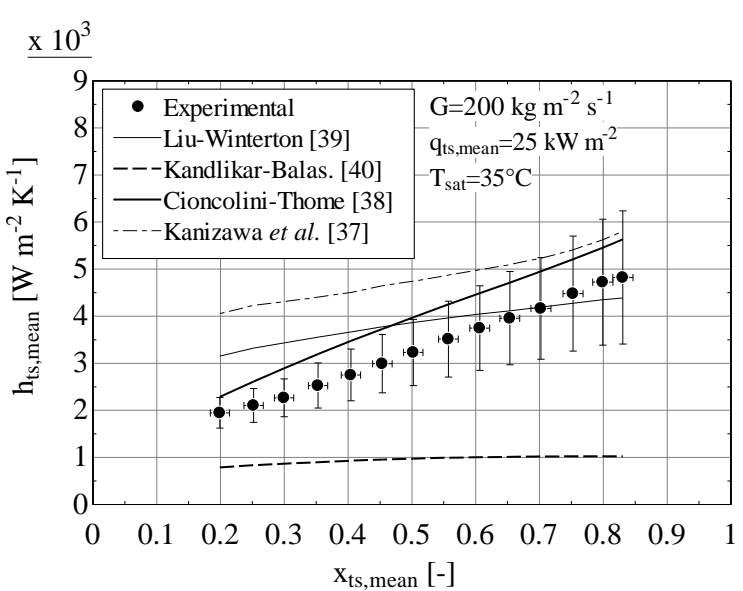

(b)

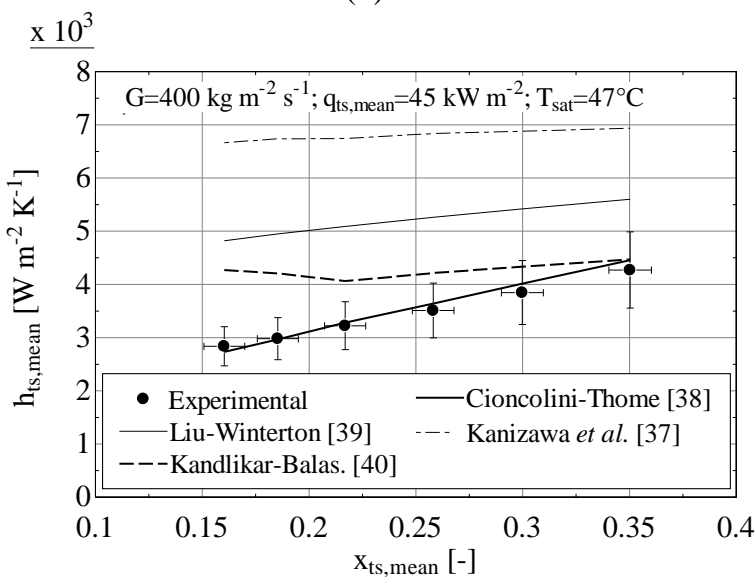

(d)

Figure 18 - Comparison of the experimental data with four heat transfer coefficient prediction methods in the literature at different conditions: (a) $G=100 \mathrm{~kg} \mathrm{~m}^{-2} \mathrm{~s}^{-1}, q_{t s}=15 \mathrm{~kW} \mathrm{~m}^{-2}, T_{s a t}=41^{\circ} \mathrm{C}$; (b) $G=200 \mathrm{~kg} \mathrm{~m}^{-2} \mathrm{~s}^{-1}, q_{t s}=25$ $\mathrm{kW} \mathrm{m}{ }^{-2}, T_{s a t}=35^{\circ} \mathrm{C}$; (c) $G=300 \mathrm{~kg} \mathrm{~m}^{-2} \mathrm{~s}^{-1}, q_{t s}=25 \mathrm{~kW} \mathrm{~m}^{-2}, T_{s a t}=41^{\circ} \mathrm{C}$; (d) $G=400 \mathrm{~kg} \mathrm{~m}^{-2} \mathrm{~s}^{-1}, q_{t s}=45 \mathrm{~kW} \mathrm{~m}^{-2}$, 